\title{
HAMBRE, DESEMPLEO Y EMIGRACIÓN. \\ LAS CONSECUENCIAS SOCIALES DE LA POLÍTICA AGRARIA AUTÁRQUICA EN ANDALUCÍA ORIENTAL, 1939-1975
}

por

\section{Francisco Cobo Romero y Teresa M ${ }^{\mathrm{a}}$. ORTEga LóPEZ}

Universidad de Granada

RESUMEN: $\quad$ El final de la Guerra Civil de 1936-1939 significó para numerosas comarcas agrarias de las provincias andaluzas orientales la puesta en práctica de una cruenta represión, que acabó violentamente con las organizaciones políticas y sindicales de izquierda. Asimismo, desde 1939, las nuevas autoridaes franquistas impusieron una férrea regulación del mercado laboral, así como una severa congelación salarial que permitió la recuperación de las ganancias empresariales en la agricultura. Sin embargo, las nefastas políticas agrarias franquistas del periodo autárquico dieron como resultado el estancamiento de la producción y la pobreza extrema de la población campesina y jornalera. El mantenimiento de una agricultura protegida y tradicional durante la década de los cincuenta y buena parte de los sesenta, unido a la acentuación del carácter periférico y a la ruralización de la economía de las provincias andaluzas orientales, tuvo fatales consecuencias en todas ellas, convirtiéndose así la masiva emigración campesina y jornalera de los años cincuenta y sesenta en el resultado más perceptible de todo lo anterior.

Palabras Clave: Represión franquista. Autarquía. Pobreza. Estancamiento agrario. Agricultura. Emigración. Andalucía.

ABSTRACT: For many agrarian districts in eastern Andalusia, the end of the Civil War of 1936-1939 brought a cruel repression that put a violent end to leftist political and union organizations. Equally, from 1939, the new Francoist authorities imposed a tough regulation of the labour market, as well as a severe salary freeze that allowed the recovery of business profits in agriculture. However, the disastrous Francoist agrarian policy of the autarchic period gave rise to stagnation in production and to extreme poverty among the rural population. The maintenance of a protected and traditional agriculture during the fifties and most of the sixties, together with the 
intensification of the peripheral and rural character of the economy of the eastern Andalusian provinces, had terrible consequences in all them. Among these consequences, the massive rural emigration of campesinos and jornaleros in the fifties and sixties was the most perceptible.

KEY WORDS: Francoist repression. Autarchy. Poverty. Agrarian economy. Agriculture. Emigration. Andalucía.

\section{Planteamientos introductorios.}

A través del presente estudio pretendemos efectuar un amplio recorrido centrado en el análisis de las transformaciones experimentadas por el sector agrícola de las provincias de Granada y Jaén, y sus consecuencias sociales más significativas, a lo largo de un extenso periodo de tiempo comprendido entre el final de la Guerra Civil y el inicio de la década de los setenta. Durante el mencionado lapso temporal, la agricultura de la Andalucía Oriental asistió impotente a la súbita interrupción de aquella dilatada fase de expansión y crecimiento situada entre 1900 y 1936 que, empujada por la creciente mercantilización de sus especializaciones productivas acontecida durante el primer tercio del siglo XX, propició una intensa readaptación relativamente modernizadora de sus estructuras y componentes. Junto a la trágica conclusión del conflicto de 1936-1939, la implantación del régimen franquista y la imposición de políticas económicas aislacionistas y autárquicas se tradujeron, en numerosas comarcas rurales de Andalucía Oriental, en el estancamiento de su sector agrario y en la parálisis padecida por la productividad de los factores y el rendimiento por unidad de superficie cultivada. En efecto, tras la dilatada coyuntura alcista experimentada de forma casi ininterrumpida por la agricultura de las provincias andaluzas orientales a partir de los comienzos del siglo XX y hasta el inicio de la guerra civil, el mencionado ciclo expansionista se vio truncado de manera abrupta. Debido, sobre todo, a la adopción por parte de las nuevas autoridades franquistas, desde al menos el año 1939 en adelante, de modelos de regulación económica fuertemente intervencionistas, que situaron al sector primario de las provincias mencionadas -y especialmente a los subsectores oleícola y cerealícola - en una crítica situación de la que no se recuperaría perceptiblemente sino hasta los últimos años de la década de los cincuenta. Si bien la guerra civil ocasionó importantes trastornos sobre la evolución de la mayor parte de las explotaciones agrícolas, la magnitud de sus repercusiones fue sensiblemente menor que la atribuida por las nuevas autoridades franquistas ${ }^{1}$. En con-

1 Cf. Garrido GonZÁlez, L.: «Producción agrícola de la España Republicana en la guerra civil», Estudios de Historia Social, Madrid, 16-17 (1981), pp. 461-514, p. 514. Del mismo autor, consúltese: «La agricultura en la Andalucía Republicana durante la Guerra Civil (1936-1939)», en Actas del III Coloquio de Historia de Andalucía. Andalucía Contemporánea, Publicaciones del Monte de

Hispania, LXIV/3, núm. 218 (2004) 1079-1112 
secuencia, queremos señalar cómo el intervencionismo económico - y la consiguiente obsesión por la regulación de los mercados de productos alimenticios- puesto en práctica durante la primera etapa de la dictadura franquista, no solamente retrasó la adaptación de la agricultura de las provincias andaluzas orientales a las exigencias cambiantes de los mercados nacional e internacional de materias primas y alimentos, sino que fue el responsable directo del estancamiento y la regresión sufridas por su sector primario hasta casi el final de los años cincuenta. El fracaso rotundo del aislacionismo económico llevado a cabo por el régimen durante la década de los cuarenta, y el reglamentismo asfixiante que imperó sobre el mercado de los principales productos agrícolas - cereales y leguminosas, aceite de oliva, vino, etc.- ocasionaron una reducción acusada de los niveles de rentabilidad de la mayoría de las explotaciones agrarias, estrechamente vinculada a la caída generalizada que experimentaron los rendimientos de sus cultivos primordiales. Asimismo, el establecimiento de precios de tasa insuficientemente remuneradores sobre determinados productos considerados básicos en la satisfacción de las necesidades alimentarias de la población, fomentó la disminución de las labores prestadas a un amplio abanico de aprovechamientos agrícolas tradicionales, el abandono de algunas superficies cultivadas o la caída estrepitosa de los rendimientos medios de casi todas ellas. Por consiguiente, las ganancias empresariales en el sector agrario -especialmente las de los medianos y grandes propietarios beneficiados por los desorbitados precios obtenidos en el mercado negro-, pudieron recuperarse de manera casi exclusiva mediante el recurso reiterado a las políticas de contención salarial o a la sobreexplotación de la mano de obra jornalera. Sobre todo si tenemos en cuenta que la notable reducción experimentada por los costos salariales, a lo largo de casi toda la década de los cuarenta, en el seno de una agricultura aún fuertemente dependiente del concurso de la fuerza de trabajo, fue posible gracias a la poderosa capacidad reguladora de las relaciones laborales ejercida por el Nuevo Estado franquista. Así como también a la destrucción sistemática a que fueron sometidos los sindicatos jornaleros existentes en la etapa anterior a la guerra civil, mediante el ejercicio de una selectiva represión, intensamente desencadenada durante los años del conflicto y la inmediata posguerra.

El sombrío panorama hasta ahora descrito apenas sufrió modificaciones destacables al iniciarse la década de los cincuenta. Sobre todo porque las políticas tímidamente liberalizadoras del sector agrario y de los mercados de alimentos puestas en marcha desde 1951 en adelante, persistieron tozudamente en el establecimiento de precios de protección, que beneficiaron de manera preferen-

Piedad y Caja de Ahorros de Córdoba, Córdoba, 1985, pp. 139-142, p. 140. Cf. asimismo CÁmARA Oficial de Comercio, Industria y Navegación de la Provincia de Granada [COCIN-G]: Memoria Comercial, 1933, y SAMANIEGO RODRíGUEZ, E: Memoria sobre la situación general de la Provincia de Granada 1937-1938, citada en M. TITOs MARTíNEZ et alii: Un siglo en la vida económica de Granada: La Cámara Oficial de Comercio, Industria y Navegación (1886-1986), Cámara Oficial de Comercio, Industria y Navegación, Granada, 1987, p. 33. 
te los cultivos tradicionales más arraigados en las especializaciones productivas de la agricultura andaluza oriental. Así pues, la persistencia de una agricultura tradicional, asentada sobre la reiterada incidencia en cultivos protegidos como el olivar, los cereales, las leguminosas y otras especies arbóreas de secano, prosiguió durante la década de los cincuenta y hasta bien entrada la década de los sesenta. La protección ofrecida por la nueva política agraria franquista en beneficio de determinadas especializaciones de cultivo de carácter tradicional, así como orientadas preferentemente a la satisfacción de la demanda interna, impidió la adaptación de la mayor parte de la agricultura de la Andalucía Oriental a las nuevas exigencias de un mercado que estaba experimentando, desde los años cincuenta en adelante, importantes modificaciones en sus pautas de consumo ${ }^{2}$. En medio de este contexto, la creciente especialización olivarera de un buen número de comarcas agrarias de la provincia de Jaén contribuyó poderosamente al afianzamiento de la explotación familiar campesina autosuficiente. A todo ello debemos unir las insoportables condiciones de vida padecidas por los jornaleros y campesinos más pobres, y los sectores de la población asalariada agrícola más castigados por los bajos salarios y la durísima represión franquista de los años cuarenta. La ausencia de alternativas de empleo generadas por un raquítico sector industrial, obligó a la mayor parte de la población jornalera de las provincias estudiadas al recurso masivo a la emigración. Este último fenómeno, suscitó un tímido proceso de mecanización de ciertas faenas agrícolas y prestaciones laborales, asociadas tanto al cultivo cerealícola como al cuidado del olivar. El resultado más palpable de todo ello, no fue otro que el de una notable disminución en los requerimientos de mano de obra jornalera exigidos por el conjunto de la agricultura de extensas comarcas del sureste español, y la consiguiente acentuación de la riada migratoria padecida por las provincias andaluzas orientales. Además, el cambio de signo experimentado hacia fines de la década de los cincuenta por la política económica sostenida por el régimen franquista, tampoco aportó soluciones dignas de mención. Las políticas franquistas de planificación indicativa y de industrialización del territorio, puestas en marcha al inicio de los sesenta, fomentaron aún más las disparidades territoriales en el reparto de las inversiones industriales. Las provincias de Granada y Jaén resultaron profundamente marginadas por las estrategias de incentivación de las inversiones industriales tanto públicas como privadas. En tales condiciones, las negativas consecuencias de las políticas económicas franquistas sobre buena parte de las provincias andaluzas orientales, se tradujeron en el incremento de la periferización y marginalización de sus sistemas productivos, que vieron acentuado de esta manera su carácter eminentemente agrario y de abastecedores de alimentos y materias primas. Sin alternativas de empleo con las que contrarrestar el creciente paro agrícola, como consecuencia de la casi

2 Cf. Barciela, C.; López Ortiz, Ma . I.; Melgarejo, J. y Miranda, J. A.: La España de Franco (1939-1975). Economía, Síntesis, Madrid, 2001, pp. 206-209. 
inexistente inversión de capitales que aquejaba al muy debilitado sector industrial - pues la aportación de la industria andaluza al conjunto nacional incluso perdió posiciones con respecto a las sostenidas antes del inicio de la guerra civil 3 - , un extenso colectivo de campesinos y jornaleros de las provincias andaluzas orientales se vio enfrentado a una calamitosa situación. Hasta el extremo que el único recurso disponible para un abultadísimo número de asalariados agrícolas con el que poder escapar del masivo desempleo estacional, de las miserables condiciones de vida y de la virtual inexistencia de expectativas de un futuro más digno, fue la emigración a las ciudades industriales y a las regiones con mayor prosperidad.

2. «AAY DE LOS VENCIDOS...'». LAS CONSECUENCIAS DE LA GUERRA CIVIL Y LA ANIQUILACIÓN DEL MOVIMIENTO JORNALERO EN LAS PROVINCIAS DE GRANADA Y JAÉN, 1936-1950.

El triunfo de las tropas rebeldes en la guerra civil, trajo consigo la implantación en todo el territorio nacional de un nuevo régimen, militarizado y dictatorial. El Nuevo Estado franquista abrazó, en una primera etapa de su andadura política, las consignas del fascismo, y practicó una violenta represión sobre amplios colectivos de jornaleros y campesinos pobres ubicados en extensas comarcas agrarias de la Andalucía Oriental, donde históricamente se había configurado un modelo de coexistencia desigualitaria entre la pequeña explotación campesina y la gran propiedad agraria.

La mayor parte de las comarcas agrarias de las provincias de Granada y Jaén registró una elevada conflictividad rural durante el período de la II República. La intensidad de la acción reivindicativa de los jornaleros perjudicó notablemente las ganancias empresariales en un periodo de crisis agraria caracterizado por la reducción del valor de las cosechas ${ }^{4}$. Durante la guerra civil, los

3 Cf. GonzÁlez de Molina, M. y Gómez Oliver, M. (eds.): Historia contemporánea de Andalucía (nuevos contenidos para su estudio), Junta de Andalucía y Caja General de Ahorros, Granada, 2000, pp. 396-397.

4 Cf. GUtiÉRrez Bringas, M. A.: «El intento de reconstruir una variante del nivel de vida del campesinado: los salarios agrícolas en España, 1756-1935", en R. ROBLEDO (ed.): VIII Congreso de Historia Agraria. Preactas, Universidad de Salamanca, Salamanca, 1997, pp. 73-90. Cf. LÓPEZ MARTíNEZ, M.: Orden público y lucbas agrarias en Andalucía. Granada, 1931-1936, Ediciones Libertarias, Madrid, 1995, pp. 170-72. Cf. asimismo COBO ROMERO, F.: Labradores, campesinos y jornaleros. Protesta social y diferenciación interna del campesinado jiennense, 1931-1936, La Posada, Córdoba, 1992. Véase también INTERNATIONAL INSTITUTE OF AGRICULTURE: The World Agricultural Situation in 1933-34. (World Agriculture: Conditions and Trends, Markets and Prices; Agricultural Policies and Conditions in the Different Countries), Villa Umberto, Roma, 1935. Véase asimismo COBO ROMERO, F. Y GONZÁLEZ DE MOLINA, M.: «Obrerismo y fragmentación del campesinado en los orígenes de la Guerra Civil en Andalucía", en M. GONZÁLEZ DE MOLINA y D. CARO CANCELA (eds.): La utopía racional. Estudios sobre el movimiento obrero andaluz, Editorial Universidad de Granada, Granada, 2001, pp. 221-282. 
logros alcanzados por el campesinado - preferentemente por los jornalerosde cara a la implantación de un nuevo orden social, fueron evidentes. Todos estos hechos alimentaron un deseo de venganza histórica traducido en la adopción de duras medidas represivas, por parte de los grupos sociales perjudicados por la acción huelguística y violenta del campesinado y los jornaleros durante los años de la República y la guerra civil, una vez que la implantación del régimen franquista dio paso a la reinstauración del tradicional orden patronal en las relaciones laborales de la agriculturas.

Así pues, la naturaleza extremadamente violenta que revistió la represión de las autoridades franquistas dirigida contra los sectores populares de buena parte de la Andalucía Oriental, y muy especialmente sobre un extenso colectivo de trabajadores agrícolas, guarda una relación estrecha con todo lo acontecido durante la década de los treinta ${ }^{6}$. Iniciado el conflicto civil, allí donde triunfaron los partidarios del golpe militar de julio de 1936, la cruenta represión respaldada por las clases patronales rurales para contrarrestar la combatividad de los jornaleros tuvo como principales víctimas a los trabajadores agrícolas y campesinos más pobres de una gran cantidad de municipios rurales ${ }^{7}$.

En la provincia de Jaén, las actividades represivas del nuevo régimen, así como la violencia institucional practicada sobre la población campesina y jornalera, aparecieron estrechamente enlazadas con la secuencia progresiva de cambio social, modernización agraria y agudización de los conflictos rurales, registrada por la sociedad y la economía jiennenses desde los comienzos del siglo XX hasta su culminación una vez finalizada la guerra civil (véase el cuadro 1). Esto explicaría la estrecha correspondencia existente entre aquellas comarcas rurales predominantemente jornaleras, con una fuerte implantación del socialismo y del sindicalismo agrario socialista, así como portadoras de una intensa conflictividad socio-laboral durante los periodos de intensa agitación huelguística del primer tercio del siglo XX, y la existencia en las mismas comarcas mencionadas de elevados índices de mortalidad violenta, resultantes de las prácticas represivas del nuevo régimen franquista. La referida secuencia situa-

5 Cf. CoBo Romero, F.: «El conflicto campesino en Andalucía durante la crisis de los años treinta (1931-1939). Un intento de revisión historiográfica», en M. GoNZÁLEZ DE MOLINA (ed.), La bistoria de Andalucía a debate. I. Campesinos y jornaleros, Anthropos, Barcelona, 2000, pp. 103-134. Cf. asimismo CAZORLA SÁNCHEZ, A.: Desarrollo sin reformistas. Dictadura y campesinado en el nacimiento de una nueva sociedad en Almería, 1939-1975, Instituto de Estudios Almerienses, Almería, 1999. Véase también López MARTíneZ, M. y GIL BraCERo, R.: Motril en Guerra. De la República al Franquismo (1931-1939). La Utopía Revolucionaria, Ediciones y Proyectos Culturales Mediterráneos, Granada, 1997.

6 Cf. Alarcón Caballero, J.: El movimiento obrero en Granada en la II República (1931-1936), Granada, Diputación Provincial, 1990. Cf. asimismo LóPEZ MARTínez, M.: Orden público y luchas agrarias..., op. cit. .

7 Cf. GIL BRACERO, R.: Guerra civil en Granada, 1936-1939 (una revolución frustrada y la liquidación de la experiencia republicana de los años treinta), Universidad de Granada, Granada, 1994, Tesis Doctoral inédita.

Hispania, LXIV/3, núm. 218 (2004) 1079-1112 
ría, pues, en una nueva dimensión el ejercicio de la violencia institucional protagonizado por las autoridades franquistas tras la conclusión de la guerra civil.

CUADRO 1. CORRESPONDENCIA ENTRE PRESENCIA JORNALERA, INTENSIDAD DEL CONFLICTO RURAL, VOTO A LA IZQUIERDA Y ALCANCE DE LA VIOLENCIA POLÍTICA EJERCIDA DURANTE LA ETAPA DE REPRESIÓN FRANQUISTA. PROVINCIA DE JAÉN, 1933-1950.

\begin{tabular}{|c|c|c|c|c|c|c|c|c|c|c|}
\hline \multirow{2}{*}{ COMARCA } & \multirow{2}{*}{1} & \multirow{2}{*}{2} & \multirow{2}{*}{3} & \multirow{2}{*}{4} & \multicolumn{2}{|c|}{$\begin{array}{c}\text { ELECCIONES } \\
1933 \\
\end{array}$} & \multicolumn{2}{|c|}{$\begin{array}{c}\text { ELECCIONES } \\
1936 \\
\end{array}$} & \multirow{2}{*}{$7^{(\mathrm{b})}$} & \multirow{2}{*}{$8^{(c)}$} \\
\hline & & & & & 5 & 6 & 5 & 6 & & \\
\hline CAMPIÑA NORTE & 11.457 & 4.167 & 8.203 & 47 & 51,98 & 47,75 & 54,28 & 45,68 & 247 & 488 \\
\hline CAMPIÑA SUR & 10.164 & 3.957 & 6.238 & 25 & 50,56 & 48,42 & 57,10 & 42,81 & 383 & 512 \\
\hline LA LOMA & 7.489 & 3.761 & 3.820 & 24 & 48,81 & 50,91 & 50,41 & 49,58 & 316 & 459 \\
\hline SIERRA SUR & 6.177 & 4.525 & 2.644 & 14 & 33,18 & 63,44 & 42,58 & 57,37 & 233 & 464 \\
\hline SIERRA MORENA & 5.649 & 1.193 & 1.631 & 15 & 50,61 & 49,06 & 56,91 & 43,09 & 185 & 310 \\
\hline EL CONDADO & 5.113 & 1.953 & 2.705 & 16 & 50,57 & 49,34 & 49,88 & 50,10 & 55 & 233 \\
\hline MÁGINA & 4.939 & 3.043 & 2.924 & 11 & 35,47 & 64,31 & 41,74 & 58,24 & 136 & 221 \\
\hline SIERRA DE SEGURA & 4.613 & 2.877 & 2.363 & 16 & 32,33 & 66,98 & 40,33 & 59,63 & 74 & 183 \\
\hline SIERRA DE CAZORLA & 3.354 & 1.570 & 1.943 & 9 & 29,31 & 69,09 & 47,46 & 52,53 & 132 & 187 \\
\hline $\begin{array}{l}\text { TOTALES Y VALORES } \\
\text { MEDIOS }\end{array}$ & 58.955 & 27.046 & 32.471 & 177 & 44,89 & 54,29 & 50,41 & 49,47 & 1.761 & 3.057 \\
\hline
\end{tabular}

Fuente: BIBLIOTECA NACIONAL (Madrid), ARCHIVO HISTÓRICO NACIONAL (Madrid), ARCHIVO DEL CONGRESO DE LOS DIPUTADOS (Madrid), BOLETÍN OFICIAL DE LA PROVINCIA DE JAÉN, ARCHIVO DE LA DIPUTACION PROVINCIAL DE JAEN, REGISTROS CIVILES de diversas localidades de la provincia de Jaén, Diarios "La Mañana», «Democracia», «Justicia», «La Ola Roja», «El Obrero de la Tierra» y «El Pueblo Católico» y Luis M. SÁNCHEZ TOSTADO (1995)8. Elaboración propia. (a). Se han contabilizado únicamente aquellos conflictos cuya localización geográfica exacta nos es conocida. (b). Se incluyen únicamente aquellos ejecutados o encarcelados cuya procedencia geográfica nos es conocida. (c). Encarcelados en la prisión provincial de Jaén cuya procedencia geográfica nos es conocida. 1. Número de jornaleros; 2 . Número de pequeños propietarios y arrendatarios agrícolas; 3. Número de afiliados a la Federación Española de Trabajadores de la Tierra (UGT); 4. Número de conflictos agrarios; 5 . Porcentaje de voto a la izquierda y al centro-izquierda; 6 . Porcentaje de voto a la derecha y al centro-derecha; 7 . Número de ejecuciones durante la etapa de represión franquista; 8 . Número de presos políticos durante la etapa de represión franquista.

8 Biblioteca Nacional (Madrid) [BN-M]: Boletín del Instituto de Reforma Agraria, (19341936), Censo de Campesinos de la Provincia de Jaén; Boletín Oficial de la ProvinCia de JaÉn [BOPJ], Años 1931, 1933 y 1936. ARChIVO DEL CONGRESO DE LOS DiPUTADOS, Leg. 141, expte. 25; ARChivo de la Diputacion Provincial De Jaen, Leg. 3.819, exptes. 6 y 7 y Leg. 3.810 , expte. 1. Diarios «La Mañana», «Democracia», «Justicia», «La Ola Roja», «El Obrero de la Tierra» y «El Pueblo Católico». ArChivo Histórico NaCional (Madrid) [AHN-Madrid]: Causa General de la Provincia de Jaén, Cajas 1.005-1.009. Pieza primera principal. Pueblos. Registros Civiles de diversas localidades de la provincia de Jaén, Libros de inscripción de defunciones. Años: 1939-1950. Cf. SÁNCHEZ TOSTADO, L. M.: «1940-1941: Hacinamiento sin precedentes en la prisión provincial de Jaén. Una aproximación al preso-tipo de la postguerra», en Boletín del Instituto de Estudios Giennenses, Jaén, 157, (Julio-Septiembre, 1995), pp. 177-195. 
Además de todo lo anterior, es preciso aludir a la acentuación de las tensiones entre los diferentes grupos sociales rurales ocasionada con motivo del desencadenamiento de la guerra civil. Una vez finalizado el conflicto, la necesidad sentida por los grupos sociales perjudicados por la revolución de reconstruir sus maltrechas economías, condujo hacia la instrumentalización de la represión del nuevo estado franquista con la finalidad de implantar el terror en amplias comarcas agrarias. Para lograr la recuperación de las ganancias capitalistas en la agricultura, y reducir a su mínima expresión la cuantía de los salarios agrícolas, era preciso aniquilar cualquier posibilidad de reconstrucción de la capacidad reivindicativa de los jornaleros. Asimismo, se imponía el exterminio físico de los integrantes de los órganos políticos y de gestión económica que actuaron durante el conflicto civil -Ayuntamientos, Consejos Municipales, Comités Populares, Comités de Colectividades, etc. ${ }^{9}$ - en contra de los intereses de la patronal agraria. Por último, con el ejercicio selectivo de la represión, se perseguía la implantación del terror, especialmente en aquellas comarcas en las que las izquierdas habían alcanzado un amplio respaldo electoral durante el periodo republicano. $\mathrm{O}$ en aquellas mismas comarcas con una fuerte presencia jornalera, y en las que la fortaleza de los sindicatos de trabajadores agrícolas había impulsado un intenso y prolongado enfrentamiento huelguístico con la patronal rural y contra los modestos y medianos propietarios o arrendatarios.

En consonancia con todo lo expuesto, estamos en condiciones de afirmar que las prácticas represivas llevadas a cabo por las autoridades militares durante la primera etapa del régimen franquista alcanzaron múltiples variantes, aún cuando el denominador común a todas ellas en las comarcas agrarias de las provincias de Granada y Jaén —así como en numerosísimos municipios rurales de casi toda Andalucía - fue la persecución de los campesinos y jornaleros más combativos y sindicalizados que participaron o impulsaron la preparación de conflictos huelguísticos antipatronales durante el periodo de la II República, como prueba el hecho de que el porcentaje de víctimas contabilizado entre la población agraria superaba, en algunos casos ampliamente, al porcentaje de población activa representado por el sector primario ${ }^{10}$ (véase el cuadro 2 ). Pero

9 Cf. AHN-Madrid: Causa General de la provincia de Jaén, Caja 1009, Pieza 3 (Cárceles y sacas); ARChivo De la Fundacion Pablo Iglesias (Madrid), Archivo de la Comisión Ejecutiva del Partido Socialista Obrero Español. Cf. asimismo: Registros Civiles de Alcalá la Real, Andújar, La Carolina, Jaén, Linares, Mancha Real, Úbeda y Villacarrillo, Libros de inscripción de defunciones, años 1936-1950.

10 El análisis de la represión franquista en Córdoba, brillantemente realizado por Francisco Moreno Gómez, demuestra cómo parte de las ejecuciones practicadas sobre campesinos cordobeses fueron sugeridas u ordenadas por ricos patronos agrícolas, que deseaban así consumar una actitud revanchista sobre el campesinado más combativo del periodo histórico precedente. Cf. MORENO GómEZ, F.: «La represión franquista a partir de los datos de Córdoba», en J. ARósTegui (coord.): Historia y Memoria de la Guerra Civil. Encuentro en Castilla y León, Vol. I., "Estudios y Ensayos», Junta de Castilla y León, Valladolid, 1988, pp. 303-329. Cf. asimismo MORENO GóMEZ, F.: «La represión en la España campesina», en J. L. GARCÍA DELGADO (ed.): El primer franquismo. España durante la Segunda 
también de todos aquellos trabajadores agrícolas que formaron parte de los comités y demás órganos de poder popular instaurados en la retaguardia durante los años de la guerra civil ${ }^{11}$. Existió, pues, una estrecha vinculación entre los actos de violencia institucional y persecución política de los jornaleros y campesinos pobres sindicalizados, o políticamente más activos durante la década de los treinta, y el deseo de la patronal agraria por destruir el poderoso entramado de organizaciones sindicales y centros de poder municipal controlados por la izquierda socialista que tanto había perjudicado sus intereses durante las conflictivas etapas de la II República y la Guerra Civil. Contribuyendo así al sometimiento del conjunto de la población asalariada agrícola a un durísimo régimen de sobreexplotación y bajos salarios, imprescindible para la recuperación de las ganancias empresariales en el sector agrícola.

CUADRO 2. CAMPESINOS Y JORNALEROS EJECUTADOS DURANTE LA REPRESIÓN FRANQUISTA EN DIFERENTES COMARCAS DE LAS PROVINCIAS DE GRANADA Y JAÉN, 1936-1950 (EN PORCENTAJES SOBRE EL TOTAL DE EJECUCIONES).

\begin{tabular}{lcc}
\hline COMARCA & $\begin{array}{c}\text { \% DE EJECUTADOS CAMPESINOS } \\
\text { Y JORNALEROS }\end{array}$ & $\begin{array}{c}\text { \% DE EJECUTADOS PERTENECIENTES A LOS } \\
\text { RESTANTES SECTORES PRODUCTIVOS }\end{array}$ \\
\hline PROVINCIA DE JAÉN & 80,15 & 19,85 \\
Sierra de Cazorla & 76,71 & 23,29 \\
Sierra de Segura & 75,40 & 24,60 \\
Mágina & 74,88 & 25,12 \\
Sierra Sur & 72,22 & 27,78 \\
Ė Condado & & 10,70 \\
PROVINCIA DE GRANADA & 89,30 & 25,20 \\
Íllora & 74,80 & 31,60 \\
Baza & 68,40 & 33,60 \\
Guadix & 66,40 & \\
Loja &
\end{tabular}

Fuente: REGISTROS CIVILES de diversas localidades de la provincia de Jaén, Libros de inscripción de defunciones. Años: 1939-1950. Rafael GIL BRACERO (1995) ${ }^{12}$. Elaboración propia.

Guerra Mundial, (V Coloquio de Historia Contemporánea de España), Siglo XXI, Madrid, 1989, pp. 189-207. Véase también ESPINOSA MAESTRE, F.: «Julio de 1936. Golpe militar y plan de exterminio", en J. CASANOVA y cols.: Morir, Matar, Sobrevivir. La violencia en la dictadura de Franco, Crítica, Barcelona, 2002, pp. 51-119. Consúltese también COBO ROMERO, F.: Conflicto rural y violencia política. El largo camino hacia la dictadura. Jaén, 1917-1950, Universidad de Jaén, Jaén, 1998, pp. 326-336.

11 Cf. COBO ROMERO, F. y ORTEGA LÓPEZ, T. Ma .: «Ser jornalero y pobre... y morir en la posguerra. El carácter selectivo de la represión franquista a través de una visión de largo recorrido, Jaén 1900-1950», en Segon CONGrès ReCerques, Enfrontaments Civils: Postguerres i Reconstruccions, vol. II, Associació Recerques, Lleida, 2002, pp. 731-755.

12 Cf. GIL BraCERO, R.: Guerra Civil en Granada, 1936-1939. Una revolución frustrada y la liquidación de la experiencia republicana de los años treinta, Tesis Doctoral inédita, Granada, Universidad de Granada, 1995. 
En consecuencia con esto último, la crudeza con que actuaron las nuevas autoridades franquistas en las labores represivas contra los vencidos en la guerra civil, guarda una relación directa con el deseo de la burguesía rural —respaldada en sus propósitos por numerosos pequeños propietarios o arrendatarios dañados por la intensa conflictividad rural previa a la contienda- por implantar una situación de acentuado terror. De esta manera, se lograba el absoluto sometimiento de los trabajadores agrícolas a las nuevas condiciones laborales de bajos salarios y prolongadas jornadas exigidas por el proceso de acumulación capitalista reconstruido tras el final de la guerra. La puesta en práctica de un terror sistematizado y selectivo, sin lugar a dudas influyó, junto con la desarticulación de los órganos sindicales de resistencia jornalera y campesina, a la acusadísima reducción que experimentaron los salarios nominales pagados en la agricultura granadina y jiennense durante casi todo el transcurso de los años cuarenta ${ }^{13}$. Pero, sin lugar a dudas, el efecto inmediato de la cruenta persecución política desplegada por la dictadura militar franquista en tierras de Andalucía Oriental, consistió en la violenta aniquilación de un poderoso movimiento sindical jornalero de carácter mayoritariamente socialista ${ }^{14}$.

Con la llegada del régimen dictatorial franquista, las provincias de Granada y Jaén, al igual que el resto de la Andalucía Oriental, acentuaron su carácter periférico dentro del ordenamiento conjunto del capitalismo español, reforzando su especialización en actividades primarias o puramente agrícolas. Este último fenómeno se debió, sobre todo durante la primera etapa de andadura del Nuevo Estado franquista, al incremento de las ganancias capitalistas en las grandes explotaciones agrarias derivado de la congelación salarial y la destrucción de los instrumentos políticos y sindicales de defensa de los jornaleros y el campesinado pobre. La abundancia de la mano de obra agrícola, así como su baratura, prefiguraron una situación de ventajas comparativas acusadamente favorecedoras de la inversión en la agricultura, y el desprecio de otras orientaciones inversoras

13 Vid. BOPJ, 19 de junio de 1939, 7 de junio de 1940, 22 de octubre de 1940, 26 de noviembre de 1940, 13 de junio de 1941, 24 de diciembre de 1941, 5 de junio de 1942, 7 de diciembre de 1942, 29 de mayo de 1943, 10 de diciembre de 1943, 30 de mayo de 1944, 3 de julio de 1944, 24 de noviembre de 1944, 9 de diciembre de 1944, 16 de diciembre de 1946, 1 de diciembre de 1947 y 11 de diciembre de 1947. Véase asimismo Bolerín OfICIAL DE LA PROVINCIA DE GrANADA [BOPG], 28 de junio de 1938, 19 de noviembre de 1940, 28 de noviembre de 1940, 19 de junio de 1941, 17 de mayo de 1947, y 1 de enero de 1948.

$14 \mathrm{El}$ nuevo estado franquista promulgó una extensa legislación orientada a la derogación de las leyes de la etapa republicana reguladoras de las relaciones laborales en la agricultura, a la supresión de los Jurados Mixtos y a la ilegalización de las organizaciones políticas y sindicales de izquierda vinculadas al Frente Popular. Vid. Decreto de 9 de marzo de 1938, Boletín OfiCial DEL EsTADo [BOE] de 10 de marzo, aprobando el Fuero del Trabajo (XIII, art. $2^{\circ}$ ); Decreto 13 de mayo de 1938 (BOE de 3 de junio) creando la Magistratura del Trabajo y suprimiendo los Jurados Mixtos (art. $1^{\circ}$ ); Decreto de 21 de abril de 1938 (BOE de 24 de abril) organizando provisionalmente los Sindicatos del Movimiento (art. $7^{\circ}$ ); Ley de 9 de febrero de 1939 (BOE del 13 de febrero) de Responsabilidades Políticas de entidades y personas contrarias al Movimiento Nacional (arts. $1^{\circ}$ y $2^{\circ}$ ).

Hispania, LXIV/3, núm. 218 (2004) 1079-1112 
destinadas a la extensión de una mínima red industrial. A partir de la década de los cincuenta, y al calor de las nuevas políticas agrarias protectoras de los cultivos tradicionales puestas en marcha por los sucesivos gobiernos, las provincias andaluzas orientales incluso incrementaron su vocación de abastecedoras de productos alimenticios altamente protegidos. La escasa evolución experimentada por la distribución de cultivos, unida al extremadamente débil crecimiento del sector industrial y la acusada concentración espacial de las actividades vinculadas al sector terciario, dibujaron un panorama desalentador en la economía de las provincias andaluzas orientales durante las décadas de los sesenta y los setenta. La emigración causó auténticos estragos entre la población rural, pero incidió especialmente sobre el colectivo de los jornaleros y trabajadores agrícolas. Pero veamos esto último con algo más de detalle.

\section{EL REFORZAMIENTO DE LA AGRICULTURA TRADICIONAL. BAJOS SALARIOS, RECUPERACIÓN DE GANANCIAS Y ACUMULACIÓN CAPITALISTA EN UNA AGRI- CULTURA ESTANCADA, 1939-1951.}

La política económica autárquica practicada por el régimen franquista durante la década de los cuarenta se instaló sobre la estricta regulación de los precios agrícolas y la férrea intervención del mercado de productos alimenticios. El interés de las nuevas autoridades franquistas por asegurar el aprovisionamiento de los mercados y garantizar un abastecimiento de productos alimenticios a precios bajos, pretendía evitar posibles procesos inflacionarios derivados del elevado coste de la mano de obra, preservando al mismo tiempo, al menos hipotéticamente, la rentabilidad de las explotaciones del conjunto de los productores agrícolas mediante el establecimiento de precios de tasa. El Servicio Nacional del Trigo creado en 1937 estuvo profundamente influido, desde su nacimiento, por una irrefutable defensa de los principios del aislacionismo y la autarquía, combinada con una hiperbólica exaltación de las virtudes de la pequeña explotación agraria. Y todo ello, a pesar de que su implantación persiguiese, en un primer momento, el otorgamiento de una clara compensación económica a los pequeños propietarios y arrendatarios trigueros de Castilla que tanto habían contribuido al triunfo del nuevo estado franquista ${ }^{15}$. Así pues, el rápido establecimiento de precios de tasa sobre la producción triguera, a fin de evitar la supuesta caída de las cotizaciones de mercado ante una erróneamente imaginada situación excedentaria, pronto se extendió hacia otros productos agrícolas primordiales en la dieta cotidiana del conjunto de la población espa-

15 Cf. BARCiela LóPEZ, C.: «Los costes del franquismo en el sector agrario: la ruptura del proceso de transformaciones. Introducción», en R. GARRABOU et alii: Historia Agraria de la España Contemporánea, Vol. III. El fin de la agricultura tradicional (1900-1960), Barcelona, Crítica, 1986, pp.

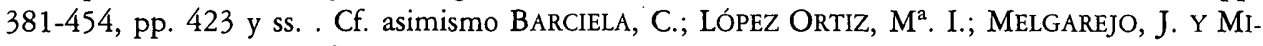
RANDA, J. A.: La España de Franco (1939-1975). Economía, op. cit., pp. 107-109. 
ñola. No obstante, el hecho de que los mencionados precios de tasa fueran inferiores a los niveles de equilibrio y rentabilidad de los cultivos, motivó el abandono de determinas orientaciones productivas, e incluso la disminución de las labores culturales prestadas a una gran cantidad de explotaciones ${ }^{16}$. Ante tan desfavorable respuesta de los factores de la producción, tan sólo una eficaz política de congelación salarial en la agricultura, instalada en el recurso a la sobreexplotación de la mano de obra jornalera, fue capaz de contrarrestar el estancamiento de las ganancias empresariales, o los perniciosos efectos de la caída de los rendimientos y el mantenimiento de bajos niveles de productividad. La drástica disminución experimentada por las importaciones de fertilizantes, y el escaso desarrollo alcanzado hasta el estallido de la guerra civil por la mecanización de numerosas labores culturales y procesos de trabajo agrícola, se conjugaron con la baratura de los costos laborales para permitir, durante la práctica totalidad de los años cuarenta, el regreso a la agricultura tradicional y orgánica, asentada sobre la incorporación de inputs energéticos de origen natural, o sobre el recurso generalizado a la mano de obra jornalera y la tracción animal ${ }^{17}$.

En las provincias objeto de nuestro estudio los resultados de la política agraria defendida por el Nuevo Estado tuvieron unos efectos tremendamente perjudiciales, no sólo para su sector primario sino también para el conjunto de su población. La irrupción de la dictadura franquista significó, pues, una trágica ruptura y un largo estancamiento que pusieron punto y final de una forma súbita a la prolongada etapa de modernización agraria iniciada en el umbral del siglo XX. Por lo que respecta a la provincia de Granada, las fuertes oscilaciones de la producción registradas en la década de los 40 se trasladaron inmediatamente al balance de los rendimientos. Así pues, si a lo largo del periodo 19001930 los rendimientos medios por hectárea en el conjunto del sector agrícola provincial habían registrado un incremento sin precedentes, como consecuencia del aumento incesante de la producción conseguido tras el proceso de modernización, si bien limitado ${ }^{18}$, que había iniciado esta provincia en los albores del

16 Cf. Barciela, C.; López Ortiz, $\mathrm{M}^{\mathrm{a}}$. I y Melgarejo, J.: «La intervención del Estado en la agricultura durante el siglo XX», en Ayer, Madrid, 21 (1996), (P. TEDDE DE LORCA, ed.: El Estado y la modernización económica), pp. 51-96.

17 José Manuel Naredo define la agricultura española de los años inmediatamente posteriores a la guerra civil como inscrita en el llamado sistema tradicional, caracterizado por el empleo de técnicas atrasadas, escasa utilización de maquinaria agrícola y abundancia de mano de obra barata. Cf. NAREDO, J. M.: La evolución de la agricultura en España (1940-1990), Editorial Universidad de Granada, Granada, 1996, pp. 118 y ss. . Cf. ABAD, C. Y NAREDO, J. M., «Sobe la «modernización» de la agricultura española (1940-1995): de la agricultura tradicional hacia la capitalización agraria y la dependencia asistencial», en C. GÓMEZ BENITO Y J. J. GONZÁLEZ RODRíGUEZ, Agricultura y Sociedad en la España contemporánea, Centro de Investigaciones Sociológicas, Madrid, 1997, pp. 249-316, véanse las pp. 251-254.

18 Con la expresión modernización limitada o moderada se ha calificado recientemente el crecimiento experimentado por la agricultura andaluza tras la crisis agraria finisecular. Cf. GONZÁLEZ DE Molina, M. y Gómez Oliver, M. (eds.): Historia contemporánea de Andalucía..., op. cit., p. 182.

Hispania, LXIV/3, núm. 218 (2004) 1079-1112 
siglo $\mathrm{XX}$, tal tendencia se vio truncada tras la finalización del conflicto de 1936-1939. Con el inicio del régimen franquista, todos los cultivos conocieron un descenso en sus rendimientos medios, siendo el caso más significativo el constituido por los cereales ${ }^{19}$. Creemos que tal situación tuvo su origen, además de en la disminución de las mejoras en el cultivo y en el conjunto de labores prestadas como respuesta a los bajos precios de tasa estipulados oficialmente para la venta en el mercado de los principales productos agrícolas, en la restricción no menos importante de fertilizantes y abonos químicos ${ }^{20}$ (véase el cuadro 3 ). En muy buena medida imputable a las severas restricciones a la importación de todo tipo de productos y a la escasez de divisas que aquejó a las arcas públicas durante la coyuntura internacional de la segunda guerra mundial ${ }^{21}$. En 1944 el informe de la Hermandad de Labradores y Ganaderos de Granada señalaba que «el problema fundamental de la agricultura granadina era la falta de abonos nitrogenados, cuya carestía perjudicaba notablemente los cultivos más necesitados» ${ }^{22}$. En sólo siete años el rígido racionamiento de que fueron objeto los fertilizantes y los abonos en general hizo que su consumo, con la única excepción del cloruro de potasa, experimentara una notable constricción en esta provincia.

CUADRO 3. CONSUMO DE FERTILIZZANTES QUÍMICOS. PROVINCIA DE GRANADA, 1935 Y 1942.

\begin{tabular}{lccc}
\hline FERTILIZANTE & 1935 (EN QMS.) & 1942 (EN QMS.) & DIFERENCIA EN \% \\
\hline Superfosfato de cal & 378.000 & 140.000 & $-62,96$ \\
Sulfato amónico & 210.000 & 9.000 & $-95,71$ \\
Nitrato sódico y cálcico & 52.000 & 20.000 & $-61,53$ \\
Sulfato potásico & 100.000 & - & $-100,00$ \\
Cloruro potásico & 10.000 & 75.000 & $+86,66$ \\
TOTALES & 750.000 & 244.000 & $-67,46$ \\
\hline
\end{tabular}

Fuente: ARCHIVO HISTÓRICO PROVINCIAL DE GRANADA23. Elaboración propia.

\footnotetext{
- 19 Cf. Cocin-G: Memorias Comerciales; años 1930-1953.

20 Para el caso de la agricultura murciana, consúltese LóPEZ ORTIZ, $\mathrm{M}^{\mathrm{a}}$. I.: «Los efectos de la autarquía en la agricultura murciana', en Revista de Historia Económica, Madrid, 3, (otoño-invierno 1996), pp. 591-618, p. 597.

21 Cf. CAtalán, J.: «Autarquía y desarrollo de la industria de fábrica durante la segunda guerra mundial. Un enfoque comparativo", en J. L. GARCíA DELGADO (ed.): El primer franquismo. Espa$\tilde{n} a$ durante la segunda guerra mundial, (V Coloquio de Historia Contemporánea e España dirigido por Manuel Tuñón de Lara), Siglo XXI, Madrid, 1989, pp. 35-88. Cf. asimismo CaTALÁN, J.: La economía española y la Segunda Guerra Mundial, Ariel, Barcelona, 1995.

22 Cf. Archivo Histórico Provincial De Granada [AHPG], Central Nacional Sindicalista-Granada [CNS-G]: Estudio Geo-Económico del Término Municipal de Granada, Hermandad de Labradores y Ganaderos de Granada, año 1944, Sección AISS, Caja 267-268.

23 Cf. AHPG; CNS-G: Estudio Geo-Económico..., op. cit. .
} 
Pensamos que tan desesperanzador panorama tuvo su origen en la nefasta política agraria de la dictadura. La caída de los rendimientos explica las continuas importaciones de trigo contabilizadas en el puerto granadino de Motril, indudablemente dirigidas a contrarrestar el déficit productivo de cereales panificables ocasionado por una estrepitosa caída de los rendimientos, así como a satisfacer la demanda alimentaria de la población de buena parte de la Andalucía Oriental. Y sólo así se explica la aparición y configuración en la provincia de Granada de un amplio mercado extraoficial del trigo que reportó, como ya ha indicado Carlos Barciela para el conjunto de España ${ }^{24}$, amplios beneficios particulares. Los extremos alcanzados por el mercado negro quedaron expuestos por el Gobernador Civil de Granada entre 1943 y 1947 cuando denunciaba, de manera enérgica, la insubordinación de la mayor parte de las autoridades locales a la hora de declarar las cantidades de trigo disponibles en sus silos, así como el reiterado incumplimiento en la aplicación de los precios oficiales de tasación ${ }^{25}$.

La agricultura jiennense conoció asimismo una situación de parálisis y estancamiento a lo largo de la práctica totalidad de la década de los cuarenta. Los malos resultados de la cosecha del año agrícola 1939-1940, quizá deban ser imputados a las específicas circunstancias socio-políticas que rodearon la coyuntura del final de la contienda y la violenta implantación, en tierras jiennenses, del nuevo régimen franquista. Así pues, el reclutamiento forzoso en zona republicana alcanzó caracteres dramáticos en la etapa final del conflicto. Un elevado porcentaje de la población masculina joven y adulta fue obligado a trasladarse a los frentes de batalla, y tras el cese de las hostilidades - logrado definitivamente a lo largo del mes de marzo de 1939- un abultado número de soldados que meses antes había sido movilizado por el Ejército Popular de la República, fue apresado por las tropas franquistas. Asimismo, varios miles de jóvenes varones en edad productiva permanecieron durante algunos meses recluidos en numerosos campos de concentración dispersos en una extensa geografía que comprendía a la misma provincia jiennense, las provincias extremeñas y algunas otras de la Andalucía Oriental. O sencillamente encarcelados en la prisión provincial, o en los múltiples establecimientos penitenciaros atestados de presidiarios que proliferaron en las poblaciones jiennenses de mayor entidad $^{26}$. Tal fenómeno ocasionó que la mano de obra necesaria para la reali-

24 Véanse de este autor algunos trabajos como: «El estraperlo de trigo en la posguerra», en Moneda y Crédito, 151, (1981), pp. 17-37 y "La España del estraperlo», en GARCíA DeLGADO, J. L. (ed.): El primer franquismo. España durante la segunda guerra mundial, Siglo XXI, Madrid, 1989, y BARCIELA, C. Y GARCÍA GONZÁlEZ, A.: «Un análisis crítico de las series estadísticas de los precios entre 1937. y 1980", en R. GARRABOU et alii: Historia Agraria de la España Contemporánea, Vol. III. El fin de la agricultura tradicional (1900-1960), Crítica, Barcelona, 1986, pp. 499-533.

25 Cf. Fontana Tarrats, J. M.: Politica granadina, Imprenta Heredera de Paulino V. Traveset, Granada, 1946, p. 12.

26 Cf. SÁNChez TOSTADO, L. M.: Historia de las prisiones en la provincia de Jaén. 500 años de confinamientos, presidios, cárceles y mazmorras, Jabalcuz, Jaén, 1997, pp. 360-366.

Hispania, LXIV/3, núm. 218 (2004) 1079-1112 
zación de las labores de cultivo y recolección se tornase acentuadamente insuficiente. Asimismo, la reducción del ganado de labor y la probable insuficiencia de semillas, provocada por la práctica paralización del sistema de transportes, incidieron negativamente sobre los resultados finales arrojados por el año agrícola 1939-1940.

A todo el conjunto de circunstancias enumerado, hay que añadir la cruenta represión desencadenada sobre la población campesina y jornalera por las nuevas autoridades franquistas ${ }^{27}$. Los fusilamientos se expandieron por la práctica totalidad de la geografía provincial. Los masivos encarcelamientos apartaron por algunos años a muchos jornaleros y minúsculos propietarios o arrendatarios de sus cotidianas tareas en torno al cultivo de la tierra. La insuficiencia de abonos químicos disponibles y los escasos estímulos al incremento de la productividad, derivados del asfixiante reglamentismo a que el Nuevo Estado sometió a los procesos de cultivo de la tierra así como a las actividades de transformación y comercialización de los productos agrícolas ${ }^{28}$, completaron un panorama caracterizado por la atonía del sector agrario y el estancamiento declarado de algunos cultivos destacados, tales como el olivar o los cereales. El estancamiento agrícola de los años 1939-1941 fue justificado por los responsables de la política agraria del nuevo régimen, mediante reiteradas alusiones a la supuesta incidencia nefasta de factores derivados de las destrucciones bélicas y la inutilización de aperos de labranza o ganado de labor y renta acontecidas durante el transcurso de la contienda de 1936-1939. No obstante, casi ninguna de las razones aducidas por el Nuevo Estado para explicar la atonía productiva del sector agrícola durante los primeros años del régimen, sostiene un análisis mínimamente riguroso de la evolución de la agricultura durante los años de la guerra civil. Como ha demostrado Carlos Tión ${ }^{29}$, el sector del olivar mantuvo desde 1936 hasta 1938 una vitalidad sorprendente, que permitió la obtención de una media de producción sensiblemente superior a la lograda durante el transcurso del lustro 1931-193530.

De igual forma, algunos documentos oficiales generados por el aparato administrativo del nuevo régimen, señalan el débil soporte empírico de la mayor parte

27 Una contabilización parcial, ha arrojado la cifra de 1.891 ejecutados durante el período 1939-1950, procedentes de la práctica totalidad de los pueblos de la provincia jiennense. Cf. COBO ROMERO, F.: La Guerra Civil y la represión franquista en la provincia de Jaén, 1936-1950, Diputación Provincial, Jaén, 1994, pp. 491 y ss. . Cf. asimismo COBO ROMERO, F.: Conflicto rural y violencia política..., op. cit. .

${ }_{28}$ Una detallada exposición de las tareas encomendadas, en la regulación del sector oleícola, al Sindicato Nacional del Olivo y a la Comisaría General de Abastecimientos y Transportes, puede hallarse en la obra de Tró, C.: La política de aceites comestibles en la España del siglo XX, Ministerio de Agricultura, Pesca y Alimentación, Madrid, 1982, p. 85 y ss. .

29 Cf. Tió, C., op. cit., p. 67 y ss. .

30 Durante el período 1936-1938, se contabilizó en todo el territorio nacional una producción global anual media de aceite situada en las 363.333 toneladas métricas, sensiblemente superior a la media del quinquenio 1931-35, situada en las 352.200 toneladas métricas. Cf. TIÓ, C., op. cit., p. 67. 
de las observaciones catastrofistas vertidas por los ideólogos y propagandistas del franquismo, llegando a sostener que el conflicto civil de 1936-39 provocó destrucciones mucho menos cuantiosas que las vaticinadas en un principio. En la Memoria de actividades elaborada por el Servicio de Recuperación Agrícola, creado en 1938 y dependiente de la Jefatura Nacional de Reforma Económica y Social de la Tierra, se indicaba que, durante la guerra, los cultivos herbáceos experimentaron una reducción del 21,5 por ciento, el olivar tan sólo del 5,3 por ciento, los frutales del 6,3 por ciento y el ganado de labor del 26,6 por ciento. Estas cuantificaciones demuestran cómo las constricciones y secuelas motivadas por el conflicto no fueron tan limitativas como inicialmente se hizo creer $^{31}$.

Todo parece mostrar, pues, que fueron los enormes costos sociales derivados de la intensa labor represiva franquista desencadenada en tierras jiennenses los que, unidos a otro tipo de factores - tales como la sobremortalidad ${ }^{32}$ asociada a la penuria generalizada y las pésimas condiciones económicas de posguerra, la probable escasez de ganado de labor, la falta de abonos químicos y repuestos para la maquinaria agrícola o la dificultosa disponibilidad de semillas-, ocasionaron la evidente quiebra del sector agrícola provincial durante la práctica totalidad de los años $40^{33}$.

El profundo letargo experimentado por la agricultura andaluza oriental durante la década de los cuarenta también se percibió en la evolución de las superficies de cultivo. En la mencionada década se detectó en las dos provincias analizadas una acusada tendencia hacia el reforzamiento del carácter tradicional de sus respectivos sectores agrícolas, asentada sobre el predominio del sistema cereal, en especial de las leguminosas, así como instalada en el estancamiento e incluso el retroceso registrado por los cultivos intensivos, las plantas industriales o el cultivo olivarero más vinculado a la comercialización de sus excedentes. La evolución registrada por las superficies destinadas a los más importantes cultivos de la agricultura jiennense durante la década de los cuarenta, nos muestra asimismo un desolador panorama de estancamiento. Los rasgos de la agricultura tradicional, basada en la importancia alcanzada por los cultivos orientados hacia la satisfacción de las necesidades alimentarias de la población rural, así como en el predominio del sistema cereal en detrimento de los cultivos industriales e intensivos o de aquellas otras orientaciones volcadas al mercado, se tornan evidentes durante el largo periodo que discurre entre 1940 y 1955. El conjunto de la superficie cultivada en la provincia jiennense, que había experimentado un prolongado crecimiento a costa de los barbechos y las superficies de montes, dehesas y pastos durante el prolongado periodo de mo-

31 Cf. Servicio De ReCuperación AGrícola, (s.f.), p. 391. Cf. asimismo Barciela, C.: «Los costes del franquismo en el sector agrario...», op. cit., p. 384.

32 Cf. Instituto Nacional De Estadística [INE]: Reseña Estadística de la Provincia de Jaén, Instituto Nacional de Estadística, Madrid, 1956, p. 116.

33 Cf. Cámara Oficial de Comercio e Industria de la Provincia de Jaén [COCI-J]: Memorias Comerciales, años 1941-1953.

Hispania, LXIV/3, núm. 218 (2004) 1079-1112 
dernización y expansión agraria que tuvo lugar en el primer tercio del siglo XX, experimentó una significativa constricción a partir de 1939. Sin lugar a dudas, el fenómeno debe ponerse en relación con las dificultades de toda naturaleza ocasionadas por el conflicto civil en tierras andaluzas. Pero asimismo resulta obligatorio condicionarlo a la desincentivación generalizada que sobre el conjunto de los pequeños y medianos cultivadores ejerció la desastrosa política autárquica de la primera etapa del régimen franquista. Tal fenómeno se muestra en toda su magnitud con respecto a las superficies destinadas al cultivo de los cereales, que tan intensamente se vieron afectados por la imposición de precios de tasa escasamente remuneradores. El año 1940, la superficie provincial destinada a cereales se vio reducida en un 30,88 por ciento con respecto a la existente el año 1933. Por el contrario, las superficies destinadas al cultivo de leguminosas; : tan decisivas en la producción de alimentos para la población rural y el gañado, así como para la fijación de nutrientes naturales sustitutivos de los abonos y fertilizantes químicos difícilmente asequibles como consecuencia de las restricčiones a la importación impuestas por la política económica autárquica, experimentarón un intenso crecimiento desde el comienzo de la década de los cuarenta.

En términos generales, las superficies cultivadas en la provincia jiennense durante la etapa autárquica del régimen franquista, no sólo interrumpieron la continuada expansión - a costa de la reducción de los barbechos y la puesta én cultivo de superficies de montes, dehesas y pastos - de la que se vieron ampliamente beneficiadas durante la larga etapa expansiva y modernizadora del primer tercio del siglo $\mathrm{XX}$, sino que asimismo conocieron una larga etapa de estancamiento íntimamente vinculada a la acentuación de sus rasgos de marcado tradicionalismo (véase el cuadro 4). El sistéma cereal, tras un corto periodo de retroceso de sus superficies cultivadas, retomó nuevos bríos a partir de 1942 ó 1943, emplazándose de nuevo en posiciones destacadas desde 1944 en adelante -ese mismo año, el sistema cereal ocupaba el 49,64 por ciento del total de la superficie cultivada-. Dentro del sistema cereal, las leguminosas ostentaban asimismo un privilegiado puesto, hasta alcanzar en 1944 una superficie que casi duplicaba la existente el año 1933. De igual manera, durante los cuarenta se vieron asimismo interrumpidos los procesos de crecimiento experimentados durante el primer tercio del siglo XX por las opciones de cultivo más claramente identificadas con una àgricultura capitalista o mercantilizada. Aún cuando debamos afirmar que el referido retroceso se debió, en muy buena medida, a la situación de bloqueo de las importaciones decretada por el Nuevo Estado franquista, y a la ausencia generalizada de fertilizantes químicos o maquinaria agrícola. En tal sentido, las plantas industriales, los cultivos leñosos e intensivos o las plantas hortícolas, pese a haber constituido orientaciones de cultivo porcentualmente poco significativas durante el periodo de modernización que discurrió entre 1900 y 1936, experimentarón una sensible caída a partir de 1940, para observar un persistente estancamiento hasta mediądos de la década de los cincuenta. Pero el rasgo más significativo de tal fenómeno quizá pueda hallarse en el virtual estancamiento registrado por las superficies des- 
tinadas al cultivo del olivar. Estas últimas, pese a haberse duplicado entre 1900 y 1933 , permanecieron virtualmente estancadas entre 1933 y 1955, cuando en éste último año empezó a atisbarse un nuevo punto de inflexión en la recuperación de las superficies destinadas a un cultivo emblemático, que abanderó el proceso de mercantilización y modernización de la agricultura jiennense durante las primeras décadas del siglo XX.

CUADRO 4. DISTRIBUCIÓN DE LAS PRINCIPALES DEDICACIONES DE LA SUPERFICIE AGRARIA PROVINCIA DE JAÉN, 1900-1955. (EN PORCENTAJES)

\begin{tabular}{lrrrrrrr}
\hline $\begin{array}{l}\text { DEDICACIÓN DE LA } \\
\text { SUPERFICIE AGRARIA }\end{array}$ & 1900 & 1933 & $\begin{array}{r}\text { VARIACIÓN } \\
1900-1933\end{array}$ & 1944 & 1949 & 1955 & $\begin{array}{c}\text { VARIACIÓN } \\
1933-1955\end{array}$ \\
\hline Cereales & 39,56 & 29,01 & $-10,55$ & 24,20 & 22,77 & 24,56 & $-4,45$ \\
Leguminosas & 5,75 & 3,51 & $-2,24$ & 6,09 & 5,96 & 5,79 & $+2,28$ \\
Barbechos & 28,75 & 18,98 & $-9,77$ & 19,35 & 19,73 & 18,10 & $-0,88$ \\
SISTEMA CEREAL & 74,06 & 51,50 & $-22,56$ & 49,64 & 48,46 & 48,45 & $-3,05$ \\
Olivar & 24,20 & 46,27 & $+18,47$ & 48,27 & 49,20 & 48,79 & $+2,52$ \\
Vid & 0,21 & 0,69 & $+0,48$ & 0,36 & 0,49 & 0,48 & $-0,21$ \\
Frutales & 0,00 & 0,04 & $+0,04$ & 0,04 & 0,04 & - & - \\
Raíces, tubérculos y bulbos & 0,58 & 0,41 & $-0,17$ & 0,42 & 0,45 & 0,78 & $+0,37$ \\
& & & & & & & \\
SUPERFICIE CULTIVADA & 50,59 & 57,72 & $+7,13$ & 57,07 & 56,94 & 58,01 & $+0,29$ \\
PASTOS, DEHESAS Y & & & & & & &. \\
MONTES & 49,41 & 42,28 & $-7,13$ & 42,93 & 43,06 & 41,99 & $-0,29$ \\
\hline
\end{tabular}

Fuente: MINISTERIO DE AGRICULTURA e INSTITUTO NACIONAL DE ESTADÍSTICA ${ }^{34}$. Elaboración propia:

En lo tocante a la agricultura granadina podemos igualmente señalar cómo la irrupción de la dictadura franquista significó también aquí una abrupta ruptura y un largo estancamiento, fenómeno éste último evidenciado en la modificación experimentada por la superficie agraria. Después de la guerra civil, el sector primario granadino acentuó su carácter de abastecedor de productos de subsistencia, regresando de nuevo al predominio del sistema cereal, al tiempo que la política autárquica paralizó su especialización en cultivos claramente vinculados a los mercados tanto internos como externos. En efecto, en líneas generales podemos decir que el primer tercio del siglo pasado se había cerrado para la provincia de Granada con un balance bastante positivo para su agricultura. Hacia el año 1933 la superficie cultivada de la provincia se había incrementado, respecto a 1900 , en un 48,61 por ciento ${ }^{35}$. La disminución de la superficie dedi-

\footnotetext{
34 Cf. Ministerio de AGricultura, Servicio de Estadística: Anuarios Estadísticos de las producciones agrícolas, años 1939-1948. Cf. asimismo INE: Anuario Estadístico de España, años 1934, 1947, 1951 y 1955.

35 Cf. INE: Anuario Estadístico de España, 1934 y JimÉnez BLANCO, J. I.: Crisis y expansión de la agricultura de Andalucía Oriental, 1874-1936, Madrid, Fundación Juan March, 1985.
}

Hispania, LXIV/3, núm. 218 (2004) 1079-1112 
cada a montes, dehesas y pastos en un total de 309.048 hectáreas durante idéntico periodo de tiempo, contribuyó en muy buena medida a la expansión de cultivos como el olivar o los cereales - trigo y cebada preferentemente ${ }^{36}$-, destinados a satisfacer la demanda alimentaria de una población en constante aumento. Otros aprovechamientos de regadío como la patata y la remolacha azucarera se convirtieron en cultivos permanentes de las vegas del interior y de la costa granadina, hasta el punto de que en 1931 triplicaban, con 6.210 y 14.337 hectáreas respectivamente, la superficie por ellos ostentada en 1900. También en ese período se apreció un significativo aumento de la superficie ocupada por los frutales y la vid, y en menor medida por las plantas hortícolas.

A partir de 1939 se desdibujó el mapa del suelo agrícola confeccionado en las décadas precedentes. El intervencionismo extremo ${ }^{37}$, impuesto por los primeros gobiernos de la dictadura franquista y la ineficacia de la propia política agraria, carente de rigor y coherencia teórica ${ }^{38}$, pusieron fin a la evolución positiva que la agricultura granadina había registrado desde los comienzos del siglo XX. El Estado franquista pretendió sustituir los mecanismos del mercado por un nuevo sistema de producción, comercialización y fijación de precios. Las autoridades comenzaron entonces a bajar y congelar por decreto los precios de los principales cultivos - $\mathrm{y}$ especialmente del trigo- hasta los niveles registrados en los años inmediatamente previos al inicio de la guerra civil, y ello en un momento claramente inflacionario ${ }^{39}$.

\footnotetext{
36 Estos tres cultivos ocupaban en 1931 el 22,77 de la superficie provincial, porcentaje que se hace mucho más significativo si tenemos en cuenta sólo la superficie cultivada al representar conjuntamente, el trigo, la cebada y el olivar, el 44,27 por ciento. Cf. JIMÉNEZ BLANCO, J. I.: La producción agraria en Andalucía Oriental, 1874-1914, (Tesis Doctoral), Universidad Complutense de Madrid, Madrid, 1986.

37 Expresión empleada por José Luis García Delgado al referirse a la política económica de los primeros lustros del régimen franquista. Cf. GARCía DelGaDO, J. L.: «Estancamiento industrial e intervencionismo económico durante el primer franquismo", en J. FONTANA (ed.): España bajo el franquismo, Crítica, Barcelona, 1986, pp. 170-191, p. 182.

38 Cf. BARCIELA, C.: «La modernización de la agricultura española y la política agraria del franquismo", en R. MORenO FonSERET Y F. SEVILlano CALERo (eds.): El Franquismo. Visiones y balances, Publicaciones de la Universidad de Alicante, Alicante, 1999, pp. 225-270, p. 234.

39 El análisis de la inflación de posguerra ha sido realizado por Manuel Jesús González. Según indica este autor, en la década de los cuarenta asistimos a una tendencia de ascensión aguda y preocupante de los precios. Durante la primera mitad de la década, los precios subieron a la velocísima tasa del 11 por ciento anual acumulativo, y en ese primer decenio todavía se destacaban tasas de subida de un 13,3 por ciento. La segunda mitad de esta década también mostró un crecimiento preocupante con un 16,6 por ciento de incremento anual acumulativo. Es más, esta etapa se cierra con la gran fiebre alcista del bienio 1950-1951, en el que los precios se elevaron en torno a un 18 por ciento en 1950 y nada menos que en un 28 por ciento en 1951. Cf. GonZÁLEZ, M. J.: «La economía española desde el final de la guerra hasta el.Plan de Estabilización de 1959», en G. ANES (ed): Historia económica de España. Siglos XIX y XX, Galaxia Gutenberg, Círculo de Lectores, Madrid, 1999, pp. 625-663, p. 634.
} 
CUADRO 5. DistribuCIÓN DE LAS PRINCIPALES DEDICACIONES DE LA SUPERFICIE AGRARIA PROVINCIA DE GRANADA, 1900-1955. (EN PORCENTAJES)

\begin{tabular}{lrrrrrrr}
\hline $\begin{array}{l}\text { DEDICACIÓN DE LA } \\
\text { SUPERFICIE AGRARIA }\end{array}$ & 1900 & 1933 & $\begin{array}{r}\text { VARIACIÓN } \\
1900-1933\end{array}$ & 1944 & 1949 & 1955 & $\begin{array}{c}\text { VARIACIÓN } \\
1933-1955\end{array}$ \\
\hline Cereales & 33,95 & 33,03 & $-0,92$ & 30,56 & 33,32 & 33,43 & $+0,40$ \\
Leguminosas & 6,24 & 6,66 & $+0,42$ & 8,99 & 8,49 & 8,24 & $+1,58$ \\
Barbechos & 45,17 & 27,97 & $-17,20$ & 23,30 & 21,08 & 21,26 & $-6,71$ \\
SISTEMA CEREAL & 85,36 & 67,66 & $-17,70$ & 62,85 & 62,89 & 62,93 & $-4,73$ \\
Olivar & 9,17 & 7,93 & $-1,24$ & 9,66 & 9,79 & 9,77 & $+1,84$ \\
Vid & 1,90 & 1,35 & $-0,55$ & 1,53 & 1,50 & 1,76 & $+0,41$ \\
Frutales & 0,17 & 2,15 & $+1,98$ & 2,35 & 2,79 & 2,55 & $+0,40$ \\
Raíces, tubérculos y bulbos & 0,69 & 1,22 & $+0,53$ & 1,30 & 0,94 & 0,70 & $-0,52$ \\
& & & & & & & \\
SUPERFICIE CULTIVADA & 29,76 & 56,31 & $+26,55$ & 50,21 & 50,20 & 56,96 & $+0,65$ \\
PASTOS, DEHESAS Y & & & & & & & \\
MONTES & 70,24 & 43,69 & $-26,55$ & 49,79 & 49,80 & 43,04 & $-0,65$ \\
\hline
\end{tabular}

Fuente: MINISTERIO DE AGRICULTURA e INSTITUTO NACIONAL DE ESTADÍSTICA ${ }^{40}$. Elaboración propia.

Esta medida provocó un gran perjuicio a los intereses materiales de los pequeños y modestos cultivadores, quienes no disponían de la capacidad suficiente para burlar los mecanismos de control de los mercados oficiales, al tiempo que ocasionó la reducción de la superficie cultivada y el paralelo aumento de las superficies de pastos, dehesas y montes respecto a los años de preguerra (véase cuadro 5). Un buen ejemplo del retroceso que supuso la política autárquica en la agricultura granadina lo tenemos en la fértil comarca de La Vega, y en concreto en el cultivo de la remolacha. La autarquía terminó por poner fin al ciclo agrícola más brillante de la mencionada comarca ${ }^{41}$. Aquélla política económica aniquiló lo que algunos estudiosos han calificado como «sistema agrícola moderno», al que se había accedido precisamente mediante la introducción y posterior extensión del cultivo de la remolacha azucarera. El cultivo aludido reportó amplios beneficios al conjunto de la provincia desde inicios del siglo XX, contribuyendo de esta manera a la renovación del utillaje agrícola, al empleo progresivo de abonos minerales, y a la suscitación de una próspera industria

40. Cf. Ministerio de Agricultura, Servicio de Estadística: Anuarios Estadísticos de las producciones agrícolas, años 1939-1948. INE: Anuario Estadístico de España, años 1934, 1947, 1951 y 1955 .

${ }_{41}$ El declive de este cultivo en Granada se inició, no obstante, a comienzos del siglo XX, especialmente tras la creación de la Sociedad General Azucarera en 1903 y sobre todo tras la fijación, el 17 de marzo de 1914, de cupos de producción de azúcar para el consumo aplicables a cada una de las fábricas establecidas en España. Cf. MARTín RodrígueZ, M.; GutiérReZ YanGUAS, M. Y PINAR SAMOS, J.: «El azúcar de remolacha: la industria que transformó la Vega de Granada», en M. Titos MARTíneZ (dir.): Historia Económica de Granada, Cámara de Comercio, Industria y Navegación de Granada, Granada, 1998, pp. 215-236, p. 228.

Hispania, LXIV/3, núm. 218 (2004) 1079-1112 
agroalimentaria con poderosos efectos en la estimulación y propagación de las inversiones dirigidas hacia otros sectores productivos. No en vano, en las primeras décadas del siglo pasado florecieron una treintena de fábricas azucareras en el entorno inmediato a la capital provincial, destinadas a la transformación de la materia prima y a la obtención de azúcar y otros derivados — pulpa, melazas, alcohol industrial, etc. ${ }^{42}$ - . Desde 1940 en adelante, los bajos precios fijados por los organismos oficiales para el cultivo de la remolacha azucarera, se convirtieron en el centro de las quejas de los productores remolacheros de la provincia. La negativa incidencia de aquéllos sobre la rentabilidad de las explotaciones y: la escasez de abonos nitrogenados que permitieran la recuperación en condiciones óptimas de la tierra, determinaron una progresiva reducción de las superficies plantadas. En 1948, con 2.790 hectáreas -un 80,53 por ciento menos que en 1931 - , se había consumado la práctica desaparición de la remolacha como cultivo característico de la agricultura de riego granadina. A partir de ese instante otra planta industrial, el tabaco, se convirtió en el cultivo regenerador de la Vega, de manera especial tras la Guerra Civil y en un momento en el que se produjo su definitiva legalización ${ }^{43}$.

Otros cultivos que también experimentaron un retroceso de su superficie cultivada fueron los cereales en su conjunto, y en particular el trigo, la cebada y el maíz. Al igual que sucedió con el cultivo de la remolacha, la estipulación de precios escasamente remuneradores para las dedicaciones cerealícolas hizo que los productores emplearan sus tierras, tal y como advertía el citado informe elaborado por la Hermandad de Labradores y Ganaderos de Granada ${ }^{44}$, en la siembra de otros productos más ventajosos para sus intereses particulares. Estos cultivos alternativos no fueron otros que el centeno y la avena - dos cereales que conocieron un avance más que significativo en los cuarenta-, las leguminosas y las plantas hortícolas. En este sentido, la escasez de alimentos y la presión demográfica sobre las zonas rurales explican en buena medida que la superficie dedicada a las leguminosas se mantuviera sin grandes variaciones durante toda la posguerra. Es más, cultivos como los garbanzos, las judías o las lentejas aumentaron espectacularmente su superficie, y de manera especial este último aprovechamiento, que duplicó en poco más de una década su número de hectáreas al pasar de las 5.135 ocupadas en 1935 a las 10.323 alcanzadas en $1948^{45}$. Pese a todo lo señalado, el estancamiento de la superficie cultivada no fue el único botón de muestra de la crisis del sector agrícola en esta provincia, pues igualmente descendieron la producción y los rendimientos por unidad de superficie de sus principales cultivos.

42 Cf. MARTín RodrígueZ, M.: Historia económica de la Vega de Granada (siglos XV-XX), Universidad de Granada, Granada, 1982.

43 Cf. González Ruiz,-i.: «El tabaco», en M. Titos Martínez (dir.): Historia Económica de Granada. Granada, Cámara de Comercio, Industria y Navegación de Granada, 1998, pp. 237-250, p. 246.

44 Cf. AHPG; CNS-G: Estudio Geo-Económico..., op. cit. .

45 Cf. INE: Anuarios Estadísticos, años 1935 y 1948. 
CUADRO 6. RENDIMIENTOS DEL OLIVAR, LOS CEREALES Y LAS LEGUMINOSAS. PROVINCIAS DE GRANADA Y JAÉN, 1926-1960. RENDIMIENTOS MEDIOS POR CADA PERIODO (EN QUINTALES MÉTRICOS POR HECTÁREA Y EN NÚMEROS ÍNDICES)

\begin{tabular}{|c|c|c|c|c|c|c|}
\hline \multirow{3}{*}{ PERIODOS } & \multicolumn{6}{|c|}{ ProvinCIA DE GRANADA (1926-1956) } \\
\hline & \multicolumn{2}{|c|}{ OLIVAR (ACEITUNA) } & \multicolumn{2}{|c|}{ CEREALES } & \multicolumn{2}{|c|}{ LEGUMINOSAS } \\
\hline & Qms./ha. & $\begin{array}{c}\text { Nos. Índices } \\
1926-1930=100\end{array}$ & Qms./ha. & $\begin{array}{c}\text { Nos. Indices } \\
1926-1930=100\end{array}$ & Qms./ha. & $\begin{array}{c}\text { Nos. Índices } \\
1926-1930=100\end{array}$ \\
\hline $1926-1930$ & 10,41 & 100,00 & 8,76 & 100,00 & 10,83 & 100,00 \\
\hline $1930-1935$ & 9,84 & 94,52 & 10,33 & 117,92 & 11,91 & 109,97 \\
\hline $1939-1950 *$ & 9,40 & 90,30 & 6,47 & 73,85 & 7,43 & 68,61 \\
\hline $1951-1956$ & 9,37 & 90,00 & 8,43 & 96,23 & 7,06 & 65,19 \\
\hline \multirow{3}{*}{ PERIODOS } & \multicolumn{6}{|c|}{ PROVINCIA DE JAÉN (1929-1960) } \\
\hline & \multicolumn{2}{|c|}{ OLIVAR (ACEITE) } & \multicolumn{2}{|c|}{ CEREALES } & \multicolumn{2}{|c|}{ LEGUMINOSAS } \\
\hline & Qms./ha. & $\begin{array}{c}\text { Nos. Índices } \\
1929-1933=100\end{array}$ & Qms./ha. & $\begin{array}{c}\text { Nos. Índices } \\
1929-1933=100\end{array}$ & Qms./ha. & $\begin{array}{c}\text { Nos: Índices } \\
1929-1933=100\end{array}$ \\
\hline $1929-1933$ & 3,26 & 100,00 & 9,14 & 100,00 & - & - \\
\hline $1944-1950$ & 2,16 & 66,26 & 6,27 & 68,60 & - & - \\
\hline $1953-1955$ & 3,21 & 98,47 & 8,92 & 97,59 & 2,89 & - \\
\hline $1955-1960$ & 2,80 & 85,89 & 10,26 & 112,25 & 4,91 & - \\
\hline
\end{tabular}

Fuente: CÁMARA OFICIAL DE COMERCIO, INDUSTRIA Y NAVEGACIÓN DE LA PROVINCIA DE GRANADA y CÁMARA OFICIAL DE COMERCIO E INDUSTRIA DE LA PROVINCIA DE JAÉN 46 . Elaboración propia. (*) No se incluyen los datos correspondientes a las campañas agrícolas $1942-1943$ y $1944-1945$.

Todo este relativo estancamiento agrario descrito, debió repercutir muy negativamente sobre el desenvolvimiento de la vida cotidiana de amplios sectores sociales del campesinado pobre y los jornaleros agrícolas de las provincias de Granada y Jaén. Los rendimientos de los principales cultivos, y muy especialmente los del olivar en la provincia jiennense, experimentaron en algunos casos fuertes oscilaciones a la baja desde 1939 en adelante, y en su conjunto, durante el periodo 1944-1950 fueron acusadamente menores que los registrados en los comienzos de la década de los treinta e incluso durante el transcurso de la guerra civil ${ }^{47}$ (véase cuadro 6). Las ganancias de los pequeños productores

46 Cf. CoCIN-G: Memorias Comerciales, años 1926-1956 y CoCI-J: Memorias Comerciales, años: 1929-1960.

47 Cf. SAmaniego Rodríguez, E.: Memoria sobre la situación general de la Provincia de Granada 1937-1938, citada por M. TITOS MARTíneZ et alii: Un siglo en la vida económica de Granada: La Cámara Oficial de Comercio, Industria y Navegación (1886-1986), Cámara Oficial de Comercio, Industria y Navegación, Granada, 1987, p. 33. Cf. asimismo GARRIDO GONZÁlEZ, L.: «Producción agrícola de la España Republicana en la guerra civil», Estudios de Historia Social, Madrid, 16-17, (Enero-Junio 1981), pp. 461-514, p. 514. Consúltese, del mismo autor: «La agricultura en la Anda-

Hispania, LXIV/3, núm. 218 (2004) 1079-1112 
y de los modestos cultivadores, sometidas a una intensa regulación administrativa, apenas despegaron durante casi toda la década de los cuarenta.

Las adversas circunstancias que rodearon a la explotación agrícola de los recursos naturales durante la primera etapa del franquismo, caracterizadas por la intervención de los precios de los principales productos mediante la fijación de tasas muy poco remuneradoras, el exhaustivo control de los intercambios y la producción o la caída sostenida de los rendimientos obtenidos por los cultivos predominantes ${ }^{48}$, desincentivaron acusadamente entre el extenso colectivo de los modestos cultivadores la introducción de mejoras susceptibles de operar en beneficio de una recuperación de las cosechas y las ganancias. Ante tan oscuro panorama, la recuperación de la rentabilidad media de las explotaciones agrarias, e incluso el inicio de un proceso prolongado de acumulación capitalista en la agricultura, fue únicamente posible mediante el reiterado recurso a la sobreexplotación de la mano de obra agrícola y la contención salarial. Esto último se vio propiciado por la sobreoferta de mano de obra asalariada y la intensa concentración de población en las comarcas rurales observada tras la conclusión de la guerra civil, tal y como registran los documentos censales de los años cuarenta ${ }^{49}$. Aún cuando a la mencionada circunstancia debamos unir la política de regulación de las relaciones laborales puesta en marcha por las nuevas autoridades franquistas y tendente a la congelación salarial, para de esta manera satisfacer los intereses de los medianos y grandes propietarios agrícolas que tan intensamente se vieron perjudicados en la agitada y conflictiva coyuntura de los años treinta. En este último sentido, la evolución experimentada por los salarios decretados para las labores de recolección de la aceituna en la provincia

lucía Republicana durante la Guerra Civil (1936-1939)», en Actas del III Coloquio de Historia de Andalucía. Andalucía Contemporánea, Publicaciones del Monte de Piedad y Caja de Ahorros de Córdoba, Córdoba, 1985, pp. 139-142, p. 140.

48 Recientemente, Thomas Christiansen ha revisado las cantidades totales de aceite de oliva ofertado al mercado y reflejado en las estadísticas oficiales, obteniendo así unas cifras relativas al aceite vendido en el mercado negro sensiblemente superiores a las contabilizadas hasta este momento. Esto último obligaría a reconsiderar la magnitud de la caída de los rendimientos, durante los años cuarenta, en el sector olivarero. Sin embargo, sus conclusiones no contradicen sustancialmente lo defendido aquí por nosotros, pues hemos efectuado, para el caso de la provincia de Granada, un cálculo de rendimientos sobre la producción de aceituna, declarada previamente a la comercialización de aceites fabricados y posteriormente vertidos al mercado. Para el caso de la provincia de Jaén, hemos empleado idéntico tipo de fuentes a las utilizadas por el autor del artículo mencionado. Cf. Christiansen, TH.: «Intervención del Estado y mercado negro en el sector oleícola durante el primer franquismo», en Historia Agraria, Murcia, 27 (agosto 2002), pp. 221-246.

49 Véase INE: Censo de la población de España y territorios de su soberanía, según el empadronamiento realizado el 31 de diciembre de 1940, Publicaciones del Instituto Nacional de Estadística, Madrid, 1941. Cf. asimismo ArChivo Hiśrórico ProvinCial de JAÉn [AHPJ], Ministerio de Industria y Comercio, Comisaría General de Abastecimientos y Transportes: Mapa Nacional de Abastecimientos. Mapa Provincial de Abastecimientos de la provincia de Jaén, 1945; AHPG, Ministerio de Industria y Comercio, Comisaría General de Abastecimientos y Transportes: Mapa Nacional de Abastecimientos. Mapa Provincial:de Abastecimientos de la provincia de Granada, 1945, Libros 5741-5746. 
de Jaén resulta sobradamente demostrativa de cuanto afirmamosso. Sin embargo, la cuestión de la evolución de los salarios pagados en la agricultura durante la década de los cuarenta merece un análisis más pormenorizado por nuestra parte, y en tal sentido procederemos a continuación (véase cuadro 7).

En primer lugar, es preciso mencionar cómo la drástica congelación a que fueron sometidos la mayor parte de los salarios agrícolas en las provincias de Granada y Jaén durante la larga década de los cuarenta fue posible gracias a la violenta desarticulación y extinción a la que fueron sometidos, tras la finalización de la guerra civil, los órganos políticos y sindicales de representación de los intereses del campesinado pobre y los jornaleros ubicados en la mayor parte de sus comarcas agrícolas. La brutal y sanguinaria represión desencadenada por las autoridades militares franquistas sobre el campesinado pobre y los jornaleros en las mencionadas provincias durante el periodo 1939-1950, eliminó de un plumazo las prácticas conflictivas sostenidas con profusión por los asalariados agrícolas granadinos y jiennenses durante el periodo 1931-1936. Al mismo tiempo que sembró el terror entre una población rural empobrecida y sometida nuevamente a unas severas prácticas de explotación patronal despiadada. En segundo lugar, debemos precisar que el mantenimiento de los salarios agrícolas, durante la práctica totalidad de la década de los cuarenta, en niveles sustancialmente inferiores a los registrados por los precios de los principales artículos de subsistencia, estuvo garantizado por la atribución de competencias absolutas en materia de regulación salarial otorgadas por el nuevo régimen franquista al Ministerio de Trabajo y sus delegaciones provinciales. Materializando así una concepción intervencionista y autoritaria en la fijación de las condiciones de trabajo, y en el control de las relaciones laborales, enteramente acorde con la ideología ultra conservadora y corporativista del nuevo régimen.

En este sentido, los salarios pagados en la recolección de la aceituna y vigentes en la provincia de Jaén, se mantuvieron estancados entre 1940 y 1944, mientras la inflación, provocada por el mercado negro y el insuficiente abastecimiento alimentario, elevaba vertiginosamente el precio de los productos básicos de subsistencia. También los salarios decretados para las labores de recolección de los cereales experimentaron una virtual congelación entre 1940 y 1947 -viéndose incluso reducidos ligeramente a partir de 1941. En términos globales, puede afirmarse que los elevados salarios de que disfrutaron los jornaleros jiennenses empleados en las labores de recolección de cereales o de la aceituna al comienzo de los años treinta, obtenidos gracias a su enorme capacidad reivindicativa y a la existencia de poderosos instrumentos sindicales de izquierda a su servicio, continuaban siendo nominalmente casi idénticos una década después. Para ser finalmente sometidos a un persistente estancamiento en beneficio de la recuperación de las ganancias empresariales en la agricultura de posguerra.

so Cf. BOPJ, 22 de octubre de 1940, 24 de diciembre de 1941, 7 de diciembre de 1942, 10 de diciembre de 1943, 24 de noviembre de 1944, 9 de diciembre de 1944, 16 de diciembre de 1946 y 1 de diciembre de 1947 .

Hispania, LXIV/3, núm. 218 (2004) 1079-1112 
CUADRO 7. COMPARACIÓN DE LAS MAGNITUDES DE LOS SALARIOS AGRÍCOLAS Y EL COSTE DE LA VIDA Y LA ALIMENTACIÓN. PROVINCIAS DE GRANADA Y JAÉN, 1932-1949. EN NÚMEROS ÍNDICES.

\begin{tabular}{|c|c|c|c|c|c|c|c|c|}
\hline \multicolumn{9}{|c|}{ PROVINCIA DE GRANADA (1932-1949) } \\
\hline \multirow[t]{2}{*}{ AÑo } & \multicolumn{6}{|c|}{ SALARIOS } & \multirow[b]{2}{*}{$\begin{array}{c}\text { Coste de la } \\
\text { Vida } \\
(1936=100) \\
(*)\end{array}$} & \multirow[b]{2}{*}{$\begin{array}{c}\text { Coste de la } \\
\text { Alimentación } \\
(1936=100) \\
(*)\end{array}$} \\
\hline & $\begin{array}{l}\text { Recolección } \\
\text { Cereales y } \\
\text { Leguminosas } \\
(1932=100)\end{array}$ & $\begin{array}{l}\text { Recolección } \\
\text { de Aceituna } \\
(1933=100)\end{array}$ & $\begin{array}{c}\text { Poda y Cava } \\
\text { de Olivos } \\
(1932=100)\end{array}$ & $\begin{array}{l}\text { Trabajos de } \\
\text { huerta } \\
(1938=100)\end{array}$ & $\begin{array}{c}\text { Trabajos de } \\
\text { Vid } \\
(1934=100)\end{array}$ & $\begin{array}{c}\text { Cultivo de } \\
\text { Tabaco } \\
(1933=100)\end{array}$ & & \\
\hline 1932 & 100,00 & 81,81 & 100,00 & - & 90,90 & 75,00 & - & - \\
\hline 1933 & 100,00 & 100,00 & 100,00 & - & 90,90 & 100,00 & - & - \\
\hline 1934 & 92,74 & 74,54 & 74,46 & - & 100,00 & 70,00 & - & - \\
\hline 1935 & 92,74 & 74,54 & 74,46 & - & 100,00 & 70,00 & - & - \\
\hline 1936 & - & - & - & - & - & - & 100,00 & 100,0 \\
\hline 1937 & - & - & - & - & - & - & - & - \\
\hline 1938 & 82,50 & - & - & 100,00 & - & 81,25 & - & - \\
\hline 1939 & 82,50 & - & - & 100,00 & - & 81,25 & - & - \\
\hline 1940 & 99,00 & 154,54 & - & 119,95 & - & 97,50 & - & - \\
\hline 1941 & 106,85 & 154,54 & - & 119,95 & - & 97,50 & - & - \\
\hline 1942 & 106,85 & 154,54 & - & 119,95 & - & 97,50 & - & - \\
\hline 1943 & 106,85 & 154,54 & - & 119,95 & - & 97,50 & 284,3 & 369,4 \\
\hline 1944 & 106,85 & 154,54 & - & 119,95 & - & 97,50 & 293,4 & 370,1 \\
\hline 1945 & 106,85 & 154,54 & - & 119,95 & - & 97,50 & 332,5 & 430,3 \\
\hline 1946 & 106,85 & 154,54 & - & 119,95 & - & 97,50 & 427,0 & 584,8 \\
\hline 1947 & 127,83 & 203,63 & - & 146,30 & - & 121,87 & 497,8 & 681,0 \\
\hline 1948 & 210,23 & 300,00 & 192,02 & 252,46 & 290,90 & 121,87 & 528,5 & 710,0 \\
\hline 1949 & 210,23 & 300,00 & 192,02 & 252,46 & 290,90 & 121,87 & 543,2 & 718,9 \\
\hline & & & PROVINCIA & DE JAÉN (19 & $32-1948)$ & & & \\
\hline AÑO & & & SALAR & & & & & \\
\hline & $\begin{array}{l}\text { Recolección } \\
\text { Cereales y } \\
\text { Leguminosas } \\
(1936=100)\end{array}$ & $\begin{array}{l}\text { Recole } \\
\text { de Ace } \\
(1932=\end{array}$ & $\begin{array}{l}\text { Pod } \\
\text { de } \\
(193\end{array}$ & $\begin{array}{l}\text { y cava } \\
\text { Olivos } \\
2=100 \text { ) }\end{array}$ & $\begin{array}{l}\text { rabajos de } \\
\text { huerta } \\
939=100 \text { ) }\end{array}$ & $\begin{array}{l}\text { Trabajos de vid } \\
(1939=100)\end{array}$ & $\begin{array}{c}\text { Coste de la } \\
\text { Vida } \\
(1936=100) \\
(*)\end{array}$ & $\begin{array}{c}\text { Coste de la } \\
\text { alimentación } \\
(1936=100) \\
(*)\end{array}$ \\
\hline 1932 & - & 100 & & 0,00 & - & - & - & - \\
\hline 1933 & 90,47 & 100 & & - & - & - & - & - \\
\hline 1934 & 80,95 & 78 & & - & - & - & - & - \\
\hline 1935 & 71,42 & 71, & & - & - & - & - & - \\
\hline 1936 & 100,00 & - & & - & - & - & 100,00 & 100,00 \\
\hline 1937 & - & - & & - & - & - & - & - \\
\hline 1938 & - & - & & - & - & - & - & - \\
\hline 1939 & 106,99 & - & & - & 100,00 & 100,00 & - & - \\
\hline 1940 & 120,66 & 106, & & - & 120,00 & 120,00 & - & - \\
\hline 1941 & 117,23 & 106, & & - & 120,00 & 120,00 & 233,8 & 281,3 \\
\hline 1942 & 117,23 & 106, & & - & 120,00 & 120,00 & 248,0 & 298,3 \\
\hline 1943 & 117,23 & 106, & & - & $120,00 \quad$ & 120,00 & 245,2 & 292,6 \\
\hline 1944 & 117,23 & 125, & & - & 120,00 & 120,00 & 250,4 & 298,9 \\
\hline 1945 & 117,23 & 125, & & - & 120,00 & 120,00 & 272,5 & 330,5 \\
\hline 1946 & 117,23 & 132 & & - & 120,00 & 120,00 & 344,6 & 445,2 \\
\hline 1947 & 201,71 & 212 & & 16,48 & 209,37 & 230,76 & 412,3 & 519,9 \\
\hline 1948 & 201,71 & 212 & & 6,48 & 209,37 & 230,76 & 457,6 & 566,4 \\
\hline
\end{tabular}

Fuente: INSTITUTO NACIONAL DE ESTADÍSTICA: Reseña Estadística de la provincia de Jaén. Madrid, 1956. BOLETÍN OFICIAL DE LA PROVINCIA DE JAÉN. Diarios «La Mañana» y «Democracia»"1.

51 Cf. BOPJ, 26 de noviembre y 16 de diciembre de 1931, 18 de octubre, 1 de noviembre, 16 y 27 de diciembre de 1932, 25 de noviembre y 5 de diciembre de 1933, 22 de mayo y 7 de noviembre de 1934; 29 de marzo de 1935 y 24 de abril de 1936. Cf. «La Mañana», (Jaén), 18 de diciembre de 1932, 1 de enero de 1933, 16 de mayo y 22 de noviembre de 1934. Cf. asimismo, "Democracia» (Jaén), 19 de junio de 1936. Consúltese también BOPJ, 19 de junio de 1939, 7 de junio de 1940, 22 de octubre de 1940, 26 de noviembre de 1940, 13 de junio de 1941, 24 de diciembre de 1941, 5 de junio de 1942, 7 de diciembre de 1942, 29 de mayo de 1943, 10 de diciembre de 1943, 30 de 
INE: RESEÑA ESTADÍSTICA DE LA PROVINCIA DE GRANADA, 1956, Madrid Instituto Nacional de Estadística. BOLETÍN OFICIAL DE LA PROVINCIA DE GRANADA52. Elaboración propia. (*) Datos referidos a la capital de la provincia.

En la provincia de Granada, las nuevas condiciones de trabajo fueron recogidas, ya muy avanzada la década de los cuarenta, en las Normas reguladoras de las condiciones de trabajo agrícola de 17 de mayo de 1947 y en la Reglamentación Provincial de Trabajo Agrícola publicada en el Boletín Oficial de la Provincia de primero de enero de 1948. En ambos casos, se estipularon subidas salariales que mantuvieron demasiado alejados a los jornales pagados en las principales faenas de la agricultura granadina de los desorbitados precios alcanzados por los principales productos alimenticios, merced a la imparable espiral inflacionista que asoló la economía española durante la segunda mitad de la década de los cuarenta y los primeros cincuenta. Pese a que los salarios agrícolas oficialmente estipulados en las Órdenes del Ministerio de Trabajo o en las Reglamentaciones laborales estuvieron muy a la zaga de los precios de los productos constitutivos de la dieta básica de los jornaleros durante todos los años cuarenta, la realidad cotidiana mostraba signos irrefutables que apuntaban al incumplimiento patronal sistemático en el pago de los salarios legalmente establecidos. Una fuente oficial como el Mapa de Abastecimientos para la provincia de Granada correspondiente al año 1945, situaba en 10 pesetas el jornal medio pagado ese mismo año en las distintas faenas agrícolas llevadas a cabo en la totalidad de los pueblos de la provincia ${ }^{53}$. Sin embargo, en aquellas comarcas agrícolas especialmente atrasadas, con un escaso peso específico de los cultivos intensivos altamente demandantes de mano de obra jornalera, y con un destacado protagonismo de los cultivos tradicionales como los cereales o las leguminosas, se llegaron a pagar durante el año 1945 salarios medios de 8,50 pesetas, incluso más bajos que los percibidos por los jornaleros de esas mismas comarcas en 1932 o 1933. Íntimamente ligado a esto último, los atropellos y abusos patronales en el cumplimiento de lo pactado en las reglamentaciones del trabajo agrícola se generalizaron en el campo granadino, una vez materializado el triunfo del nuevo régimen tras la finalización del conflicto de 19361939. El propio gobernador civil de la provincia, Fontana Tarrats, indicaba cómo los propietarios agrícolas seguían en 1947 pagando a sus obreros, bajo amenaza de no volver a ser contratados, los antiguos jornales de 4,50 a 6,00 pesetas estipulados en las bases de los años 1934 y $1935^{54}$. En tales circunstancias, el hambre

mayo de 1944, 3 de julio de 1944, 24 de noviembre de 1944, 9 de diciembre de 1944, 16 de diciembre de 1946, 1 de diciembre de 1947 y 11 de diciembre de 1947.

52 Cf. BOPG, 23 de junio de 1932, 13 de mayo de 1933, 5 de junio de 1934, 28 de junio de 1938, 19 y 28 de noviembre de 1940, 19 de junio de 1941, 17 de mayo de 1947 y 1 de enero de 1948.

53 Cf. AHPG, Ministerio de Industria y Comercio, Comisaría General de Abastecimientos y Transportes: Mapa Nacional de Abastecimientos. Mapa Provincial de Abastecimientos de la provincia de Granada, 1945, Libros 5741-5746.

s4 Cf. THOMÀs, J. M.: José María Fontana Tarrats. Biografía política d'un franquista català, Centre de Lectura, Reus, 1997, p. 95.

Hispania, LXIV/3, núm. 218 (2004) 1079-1112 
ocasionado por las constricciones en la producción, la galopante inflación y los prohibitivos precios del mercado negro, deterioraron las condiciones de vida de los sectores más humildes de la población rural.

\section{El final de un largo trayecto. Persistencia de la agricultura TRADICIONAL, DESEMPLEO AGRÍCOLA Y EMIGRACIÓN, 1951-1975.}

La aniquilación del movimiento jornalero llevada a cabo de manera virulenta en una gran cantidad de comarcas agrarias de las provincias andaluzas orientales - y especialmente de las de Granada y Jaén- durante los años de la guerra civil, y sobre todo, a lo largo de la década de los cuarenta, corrió paralela a la reconstrucción del tradicional orden patronal en las relaciones laborales agrícolas. Esto último conllevaba la aplicación de un modelo de recuperación de las ganancias de los cultivadores - sobre todo medianos y grandes- asociado, como hemos tenido ocasión de comprobar de manera fehaciente, al recurso a la congelación de los salarios pagados a los jornaleros, y a la elevación constante de los precios de los productos alimenticios en el mercado negro. Hasta tal extremo, que puede afirmarse cómo la agricultura constituyó una fuente de trasvase de capitales no inflacionista destinada a la financiación del sector industrial durante la década de los $40^{55}$. La penuria extrema padecida por los campesinos más pobres y los jornaleros se conjugó con el terror y la violencia institucional ejercidos por las nuevas autoridades franquistas, para alumbrar como resultado la eliminación de cualquier posibilidad de resurgimiento de la conflictividad huelguística, o la simple protesta laboral, en el ámbito de la agricultura granadina y jiennense ${ }^{56}$.

Este panorama, ciertamente ensombrecedor, experimentó escasas variaciones durante la década de los cincuenta, e incluso durante los comienzos de la década de los sesenta, al menos por lo que respecta a la ausencia casi absoluta

ss Cf. ABAD, C. Y NAREDO, J. M., «Sobe la «modernización» de la agricultura española...», op, cit., pp. 251-254.

56 Los salarios pagados en la recolección de la aceituna y vigentes en la provincia de Jaén, se mantuvieron estancados entre 1940 y 1944, mientras la inflación provocada por el mercado negro elevaba vertiginosamente el precio de los productos básicos de subsistencia de la población jornalera. Los referidos salarios experimentaron subidas poco significativas a partir de 1945, aún cuando los índices de elevación salarial continuaran manteniéndose muy lejos de los disparados índices del costo de la vida o de los precios alcanzados por los productos alimenticios de primera necesidad. También los salarios decretados para las labores de recolección de los cereales experimentaron una virtual congelación entre 1940 y 1947 — viéndose incluso reducidos ligeramente a partir de 1941. Cf. BOPJ, 26 de noviembre y 16 de diciembre de 1931, 18 de octubre, 1 de noviembre, 16 y 27 de diciembre de 1932, 25 de noviembre y 5 de diciembre de 1933, 24 de abril de 1936. "La Mañana", (Jaén), 18 de diciembre de 1932, 1 de enero de 1933, 16 de mayo y 22 de noviembre de 1934. «Democracia» (Jaén), 19 de junio de 1936. Cf. asimismo BOPJ, 19 de junio de 1939, 7 de junio de 1940, 22 de octubre de 1940, 26 de noviembre de 1940, 1 y 11 de diciembre de 1947. 
de conflictividad en el seno de la agricultura de las provincias andaluzas orientales. Los devastadores efectos de la represión franquista sobre el poderoso movimiento sindical jornalero de los años treinta, y las consecuencias sociales de las políticas agrarias franquistas iniciadas con la década de los cincuenta, y condensadas de manera primordial en la drástica reducción de la población asalariada agrícola, actuaron como elementos determinantes. Insistamos, acto seguido, en esto último. Pese a las intenciones liberalizadoras de la producción agraria y el comercio de productos alimenticios proclamadas por el Ministerio de Agricultura a partir de 1951, en líneas generales, la política agraria franquista de los años cincuenta no abandonó enteramente el sistema autárquico de intervención y regulación de los mercados. No obstante, los auténticos efectos de la nueva política agraria franquista tardarían aún mucho tiempo en hacerse visibles en las provincias andaluzas orientales. En casi todas ellas persistió, durante la década de los cincuenta y bien avanzada la de los sesenta, un modelo de agricultura tradicional, asentada sobre la supremacía indiscutible de los cultivos mediterráneos escasamente adaptados a las nuevas exigencias de los mercados - nacional e internacional-, así como sobre la persistencia de bajos niveles de rendimiento y productividad. La fijación de elevados precios, altamente remuneradores, y en el marco de una agricultura protegida y escasamente competitiva, permitió que la distribución de cultivos en las provincias de Granada y Jaén experimentase tan sólo leves modificaciones a lo largo del periodo que discurrió entre 1951 y 1965. A ello debe unirse la legislación promulgada durante casi toda la década de los cincuenta, encaminada a favorecer la expansión de las superficies destinadas al cultivo del olivar y otras especies arbóreas o arbustivas - ley de 1 de julio de 1951 de «Repoblaciones en el litoral Este y Sur»- o a impulsar el incremento de la productividad de los olivares ya plantados - decreto de 23 de noviembre de 1956 de «Fomento de la producción de aceites- ${ }^{57}$. Como consecuencia de todo ello, en ambas provincias continuaron predominando los cereales y las leguminosas, junto con el olivar - de manera especial en la provincia de Jaén- sobre el resto de las dedicaciones de la superficie cultivada. Así pues, y por lo que respecta a la última de las provincias mencionadas, es preciso señalar cómo en la agricultura jiennense, a lo largo de los años cuarenta, cincuenta y sesenta, el olivar fue expandiéndose de forma constante, hasta ocupar el 51 por ciento de la superficie cultivada en 1962 y el 55,88 por ciento de la misma el año $1972^{58}$. La vitalidad expansiva del cultivo olivarero, incidió notablemente en la acentuación de un fenómeno mostrado por la estructura social rural de la provincia que ya comenzó a atisbarse durante el primer tercio del siglo XX. Nos referimos a la

57 Cf. Ley de 1 de julio de 1951 y Decretos de 26 de noviembre de 1954, 1 de febrero de 1957 y 7 de marzo de 1958. Cf. asimismo el Decreto de 23 de noviembre de 1956 y las Órdenes de 8 y 9 de enero de 1957. Al respecto, consúltese Tió, C.: La política de aceites comestibles..., op. cit., pp. 124-128.

58 Cf. MARTín MESA, A.: Los cambios estructurales del sector agrario jiennense en el periodo intercensal 1962-1972, Cámara Oficial de Comercio e Industria de la Provincia, Jaén, 1983.

Hispania, LXIV/3, núm. 218 (2004) 1079-1112 
exitosa adaptabilidad de la pequeña explotación campesina en torno a un cultivo exigente en prestaciones de mano de obra requeridas para la realización de determinadas faenas estacionales, así como relativamente poco demandante de insumos proveídos por la industria. En muy buena medida debido a la expansión del olivar, y a su proverbial adaptabilidad a la pequeña tenencia campesina de carácter autosuficiente, en las comarcas agrarias jiennenses más intensamente cultivadas de las campiñas norte y sur, Sierras del Sur o La Loma, las pequeñas explotaciones familiares de menos de 20 hectáreas ocupaban, a la altura del año 1971, significativos porcentajes de superficie. En algunos casos situados entre el 31,12 y el 35,88 por ciento de las tierras provinciales censadas, y muy superiores al porcentaje medio de superficie agraria acaparado por las pequeñas explotaciones rústicas en el conjunto de las tierras de la provincia ${ }^{59}$. Fueron precisamente estas mismas pequeñas explotaciones agrícolas con menos de 20 hectáreas de superficie, las que en 1971 acaparaban el 46,74 por ciento de la superficie olivarera provincial, aun cuando tan sólo representasen, superficialmente, el 23,41 por ciento del total de las tierras censadas ese mismo año para el conjunto de la provincia ${ }^{60}$.

59 Si tenemos en cuenta exclusivamente las tierras labradas, las explotaciones familiares de menos de 20 hectáreas en la provincia de Jaén ocupaban, en 1972, el 43,2 por ciento del total provincial de las mismas, evidenciando así la enorme importancia alcanzada por las modestas explotaciones campesinas en el conjunto de las tierras provinciales sometidas a un aprovechamiento agrícola. En la provincia de Granada acontecía algo parecido, pues las explotaciones campesinas con una superficie inferior a las 20 hectáreas acaparaban el 40,5 por ciento de las tierras provinciales labradas. Cf. ORganización SindiCAL: Consejo Económico Social de la provincia de Jaén (IV Pleno), Jaén, 1971. Cf. asimismo MARTíneZ SierRA, F.: Cambios estructurales en el sector agrario de Andalucía Oriental, 1960-1975, Instituto de Desarrollo Regional, Sevilla, 1985, p. 41.

60 Es más, la especialización olivarera de la pequeña explotación (0-20 has.) se hizo patente desde los años sesenta en adelante. En 1962, el 62,90 por ciento de la superficie cultivada reunida por el conjunto de las pequeñas explotaciones se destinaba al olivar, porcentaje que se elevaría hasta el 72,35 por ciento en 1972. Por el contrario, las grandes explotaciones de más de 100 hectáreas, destinaban el 49,40 por ciento de su superficie cultivada al olivar en 1962 , y el 56,80 por ciento de la misma en 1972. Efectuando un cómputo global de las tierras provinciales destinadas al cultivo del olivar y su distribución entre las explotaciones de distinto tamaño, obtendríamos los siguientes resultados: el año 1962, las pequeñas explotaciones situadas entre las 0 y las 20 hectáreas reunían el 46,8 por ciento de la superficie provincial ocupada por el olivar, mientras el año 1972, esas mismas explotaciones reunían el 48 por ciento de la misma. Estos porcentajes cobran aún mayor importancia si tenemos en consideración que eran precisamente las pequeñas explotaciones agrícolas las que concentraban el grueso de las tierras labradas provinciales. Esto último se hace mucho más comprensible si se tiene en cuenta que en 1971 las pequeñas explotaciones reunían el 42,06 por ciento de las tierras labradas en toda la provincia, mientras que las grandes explotaciones de más de 100 hectáreas reunían tan sólo el 27,45 por ciento de las tierras labradas, y nada más y nada menos que el 93,08 por ciento de las no labradas. Cf. ORGanización SindiCAL: Consejo Económico Social de la provincia de Jaén (IV Pleno), Jaén, 1971, pp. 36-37. Cf. asimismo, INE: Ier. Censo Agrario. Cuadernos Provinciales (Jaén), Madrid, 1962 y $I I^{\circ}$ Censo Agrario. Cuadernos Provinciales (Jaén), Madrid, 1972. Véase también MARTÍN MESA, A.: Los cambios estructurales del sector agrario jiennense..., op. cit., pp. 60-63. 
La supremacía del olivar en la agricultura jiennense de las décadas de los cincuenta, los sesenta y los setenta estuvo compartida por el significativo peso representado por el sistema cereal. Por lo que respecta a este último, es preciso señalar su retroceso, aún cuando se registrase de una manera lenta y tardía tan sólo a partir de los comienzos de la década de los cincuenta. El sistema cereal, integrado por los cereales - trigo, cebada, centeno y avena, básicamente-, las leguminosas - garbanzos, habas, judías y lentejas, sobre todo- y los barbechos, ostentaba todavía en 1951 la significativa cifra del 49,28 por ciento de la superficie provincial cultivada. Si bien desde entonces experimentó un constante debilitamiento ante la hegemonía indiscutida de las tierras con dedicación olivarera. En 1962, la importancia de las tierras ocupadas por el sistema cereal se había reducido hasta el 44,9 de la superficie provincial cultivada, mientras que en 1972, estas mismas tierras significaban todavía un considerable 35,2 por ciento de la superficie agraria útil de la provincia. El paisaje agrario granadino también mostró acusadas tonalidades de perdurabilidad de una agricultura de corte tradicional, al menos hasta los inicios de la década de los setenta. A pesar del avance registrado por el olivar en casi toda la geografía provincial, y especialmente en la segunda mitad de la década de los sesenta ${ }^{61}$, el sistema cereal continuaba ocupando una privilegiada posición en la distribución de cultivos todavía a la altura del año $1970^{62}$. En esa última fecha, las tierras barbechadas y las destinadas al cultivo de cereales y leguminosas alcanzaban un nada despreciable 71,94 por ciento del total de las tierras provinciales sometidas a un aprovechamiento agrícola ${ }^{63}$. Este fenómeno de tozuda resistencia de las tierras cerealícolas a reducir su presencia en medio de una agricultura predominantemente tradicional, incidió sobre aquel otro consistente en la masiva expulsión de mano de obra agrícola jornalera que conocieron las provincias de Granada y Jaén desde los años cincuenta en adelante. De manera especial porque, en el transcurso de las décadas de los cincuenta y los sesenta, las tierras cerealícolas fueron concentrándose primordialmente en las explotaciones de tamaño medio y grande - y especialmente en estas últimas - las mismas que conocieron un proceso más intenso de mecanización de determinadas labores tradicionalmente intensivas en mano de obra agrícola asalariada ${ }^{64}$.

61 En 1967 la provincia de Granada pasó a ocupar un destacado puesto entre las principales provincias productoras de aceite de oliva, situándose en el noveno lugar en cuanto a superficie destinada al cultivo del olivar ( 95.540 hectáreas), y el sexto en cuanto a producción de aceite y aceituna (1.170 Quintales métricos de aceituna y 60.000 Quintales métricos de aceite). Cf. COCIN-G: Memoria Comercial, 1965-1970, Granada, 1971, p. 128.

62 Cf. Ibídem, p. 127.

63 Cf. Bosque Maurel, J. y Ferrer RodrígueZ, A.: Granada, la tierra y sus bombres, Editorial Universidad de Granada, Granada, 1999, p. 352.

64 Por lo que respecta a la provincia de Jaén, es preciso señalar cómo en 1962, los cultivos cerealícolas y los barbechos asociados a los mismos, ocupaban la muy significativa cifra del 68,3 por ciento del conjunto de las tierras labradas reunidas por las grandes explotaciones de más de 100 hectá- 
La conjugación de las dos circunstancias descritas en el transcurso de un largo periodo que discurrió aproximadamente entre 1951 y 1975 - a saber, expansión olivarera acentuadamente concentrada en las pequeñas explotaciones campesinas en su mayoría autosuficientes, y persistencia de un cultivo cerealícola crecientemente mecanizado en las explotaciones de mediano y gran tamaño inmersas en una agricultura tradicional ${ }^{65}$ - , arrojó decisivas consecuencias. Siendo la más visible de todas ellas, en infinidad de comarcas agrarias de Andalucía Oriental, la extremada reducción padecida por las ofertas de empleo dirigidas hacia una abultada población jornalera. A todo ello debe unirse el fenómeno de la progresiva mecanización de determinadas labores prestadas al olivar - labores de arado y bina, preparación de suelos, realización de ruedos, etc.- - posibilitado por la creciente utilización de tractores y arados de tracción mecánica, asimismo proporcionados por una extensa gama de cooperativas ${ }^{\prime}$ empresas auxiliaras agrícolas, de la que resultó beneficiada una considerable proporción de pequeñas explotaciones campesinas ${ }^{66}$. En suma, pues, una ingente cantidad de mano de obra jornalera radicada en extensas comarcas agrarias de las provincias andaluzas orientales de Granada y Jaén, se vio constreñida al recurso generalizado a la emigración desde mediados de la década de los cincuenta en adelante (véase cuadro 8). El único disponible por un abultado colectivo de trabajadores agrícolas acosado por el desempleo estacional, los bajos salarios y la imparable disminución de las necesidades de mano de obra asalariada requeridas por una agricultura crecientemente capitalizada, e imposibilitado para la obtención de empleos alternativos en un raquítico sector industrial con una presencia a lo sumo testimonial ${ }^{67}$.

reas, mientras en 1972, ese mismo porcentaje de tierras cerealícolas, se elevaba todavía hasta el 64,25 por ciento del total de tierras labradas por las grandes explotaciones con 100 hectáreas o más. En el extremo opuesto, el año 1972, las tierras labradas reunidas por las pequeñas explotaciones de menos de 20 hectáreas, dedicaban tan sólo el 32,3 por ciento de su superficie al cultivo de los cereales. Cf. INE: Censos agrarios de 1962 y 1972. Resultados provinciales (Provincia de Jaén), Madrid, 1962 y 1972.

65 El número de cosechadoras existentes en la provincia de Granada evolucionó desde las 67 contabilizadas el año 1961 hasta las 687 registradas el año 1970. El incremento fue, pues, espectacular, situándose así en el 1.025,37 por ciento. Cf. CONFEDERACión ESPAÑOLA DE CAJAS DE AHORROS: Situación actual y perspectivas de desarrollo de Andalucía Oriental, Tomo II: «Análisis de los sectores productivos», Madrid, 1974, pp. 176 y ss. .

66 En la provincia de Jaén, el parque de tractores pasó de los 1.268 existentes en 1962 a los 5.763 contabilizados en 1972. Es más, en el periodo intercensal comprendido entre 1962 y 1972, el porcentaje de tractores usados en las pequeñas explotaciones de menos de 20 hectáreas, pasó de significar el 6,0 por ciento del total a representar el 23,1 por ciento del total de los utilizados en la agricultura provincial el último año mencionado. Cf. MARTín MESA, A.: Los cambios estructurales en el sector..., op. cit., pp. 82-86. Cf. asimismo CONFEDERACIÓN ESPAÑOLA DE CAJAS DE AHORROS: Situación actual y perspectivas de desarrollo de Andalucía Oriental, Tomo II: "Análisis de los sectores productivos», Madrid, 1974, pp. 168-176 y ORGANIZACIÓN SINDICAL: Consejo Económico Social de la provincia de Jaén (IV Pleno), op. cit., p. 42.

67 Cf. CÁMARAS DE COMERCIO, INDUSTRIA Y NAVEGACIÓN DE ANDALUCÍA [COCINA]: Estructura económica de Andalucia (Memoria económica), Cámaras de Comercio, Industria y Navegación de Andalucía, 
CUADRO 8. DISTRIBUCIÓN DE LOS TRABAJADORES EMIGRADOS POR CATEGORÍA PROFESIONAL. ANDALUCÍA ORIENTAL Y ESPAÑA, 1961-1974. (EN PORCENTAJES)

\begin{tabular}{|c|c|c|c|c|c|c|}
\hline \multirow[b]{2}{*}{ Categoría profesional } & \multicolumn{6}{|c|}{ PERÍODO 1961-1965 } \\
\hline & Almería & Granada & Jaén & Málaga & $\begin{array}{c}\text { Andalucía } \\
\text { Oriental }\end{array}$ & España \\
\hline Empresarios y altos cargos & 0,7 & 1,2 & 0,4 & 1,7 & 0,9 & 1,7 \\
\hline Profesionales, técnicos y afines & 3,7 & 3,5 & 3,2 & 6,0 & 3,7 & 5,5 \\
\hline Servidores domésticos y subalternos & 6,9 & 5,9 & 8,2 & 7,1 & 6,7 & 11,1 \\
\hline Empleados, administrativos y similares & 3,7 & 4,1 & 4,1 & 3,9 & 3,8 & 4,7 \\
\hline \multirow{2}{*}{ Jornaleros y asalariados agrícolas } & 84,9 & 85,3 & 84,1 & 81,2 & 81,2 & 77,0 \\
\hline & \multicolumn{6}{|c|}{ PERÍODO 1971-1974 } \\
\hline Categoría profesional & Almería & Granada & Jaén & Málaga . & $\begin{array}{l}\text { Andalucía } \\
\text { Oriental }\end{array}$ & España \\
\hline Profesionales y técnicos & 6,9 & 4,5 & 5,2 & 7,7 & 5,6 & 7,4 \\
\hline Personal administrativo & 6,4 & 4,8 & 5,7 & 7,0 & 5,7 & 8,4 \\
\hline Comerciantes y vendedores & 2,7 & 3,2 & 2,8 & 4,4 & 3,2 & 4,1 \\
\hline Trabajadores de los servicios & 5,7 & 7,9 & 7,0 & 8,1 & 7,3 & 7,0 \\
\hline Agricultores, ganaderos y pescadores & 18,5 & 15,9 & 10,3 & 9,4 & 13,1 & 17,3 \\
\hline Trabajadores de la industria no agraria & 55,2 & 60,1 & 65,6 & 58,1 & 61,2 & 51,3 \\
\hline Otros activos & 4,7 & 3,5 & 3,3 & 5,3 & 3,9 & 4,5 \\
\hline
\end{tabular}

Fuente: CÁMARAS DE COMERCIO, INDUSTRIA Y NAVEGACIÓN DE ANDALUCÍA68. Elaboración propia.

Tal y como prueban fehacientemente los datos obtenidos en la provincia de Jaén, el monocultivo olivarero, y la íntima asociación que se fue estableciendo entre la especialización en torno al olivar y la pequeña explotación campesina autosuficiente, se convirtieron durante las décadas de los cincuenta y los sesenta en los factores más directamente responsabilizados en la expulsión de mano de obra jornalera y emigrante dirigida hacia otras regiones peninsulares económicamente más prósperas (véase cuadro 9). Así pues, puede afirmarse que cuanto más intensa fue la especialización comarcal en el cultivo del olivar, mayor fue la cantidad de población jornalera expulsada de sus municipios de origen.

Jaén, 1978, pp. 137-138. Véase asimismo ORganizACión SINDICAL: Consejo Económico-Social de la Penibética. Factores bumanos y sociales de desarrollo, II Pleno, Granada, 1974.

68 Cf. Cocina: Estructura económica de Andalucía (Memoria económica), Jaén, 1978, pp. 137-138. 
CUADRO 9. ESPECIALIZACIÓN OLIVARERA Y EVOLUCIÓN DEMOGRÁFICA EN LOS DISTINTOS TIPOS DE MUNICIPIOS. PROVINCIA DE JAÉN, 1945-1975

\begin{tabular}{|c|c|c|c|c|c|c|c|c|c|c|}
\hline \multirow{3}{*}{$\begin{array}{l}\text { Clasificación municipal. } \\
\% \text { superficie olivarera sobre el total } \\
\text { de la superficie del término } \\
\text { municipal cultivada }\end{array}$} & \multicolumn{10}{|c|}{$\begin{array}{l}\text { POBLACIÓN DE DERECHO } \\
\text { EN NÚMEROS ABSOLUTOS Y EN NÚMEROS ÍNDICES. } 1945=100\end{array}$} \\
\hline & \multicolumn{2}{|c|}{1945} & \multicolumn{2}{|c|}{1950} & \multicolumn{2}{|c|}{1960} & \multicolumn{2}{|c|}{1970} & \multicolumn{2}{|c|}{1975} \\
\hline & $\begin{array}{l}\mathrm{N}^{\circ} \text {. } \\
\text { Habs. }\end{array}$ & Índice & $\begin{array}{l}\mathrm{N}^{\circ} . \\
\text { Habs. }\end{array}$ & Índice & $\begin{array}{l}\mathbf{N}^{\circ} \text {. } \\
\text { Habs. }\end{array}$ & Índice & $\begin{array}{l}\text { No. } \\
\text { Habs. }\end{array}$ & Índice & $\begin{array}{l}N^{\circ} \text {. } \\
\text { Habs. }\end{array}$ & Índice \\
\hline $\begin{array}{l}\text { Municipios intensamente olivareros } \\
(\bullet 66,66 \%)\end{array}$ & 203.367 & 100,00 & 198.609 & 97,66 & 182.023 & 89,50 & 150.441 & 73,98 & 142.139 & 69,89 \\
\hline $\begin{array}{l}\text { Municipios medianamente olivareros } \\
(33,33 \%-66,66 \%)\end{array}$ & 307.289 & 100,00 & 308.716 & 100,46 & 293.736 & 95,59 & 263.640 & 85,80 & 254.958 & 82,97 \\
\hline $\begin{array}{l}\text { Municipios escasamente olivareros } \\
(\bullet 33,33 \%)\end{array}$ & 268.672 & 100,00 & 273.903 & 101,95 & 271.182 & 100,93 & 254.125 & 94,59 & 254.183 & 94,61 \\
\hline TOTAL PROVINCIAL & 779.328 & 100,00 & 781.228 & 100,24 & 746.941 & 95,84 & 668.206 & 85,74 & 651.280 & 83,56 \\
\hline
\end{tabular}

Fuente: ARCHIVO HISTÓRICO PROVINCIAL DE JAÉN; INSTITUTO NACIONAL DE ESTADÍSTICA e INSTITUTO DE ESTADÍSTICA DE ANDALUCIA 69 . Elaboración propia.

La disminución de la población activa agraria en las provincias de Granada y Jaén, tanto en cifras absolutas como en términos porcentuales sobre el total de la población ocupada, alcanzó elevadas expresiones numéricas entre 1955 y 1975. La primera de las provincias mencionadas perdió en el transcurso de tiempo descrito un total de 81.501 activos agrarios, mientras que durante idéntico periodo la provincia jiennense vio disminuir su población agraria en nada más y nada menos que 116.910 activos $^{70}$. Como hemos señalado más arriba, la inmensa mayoría de las pérdidas sufridas por la población empleada en la agricultura de las provincias andaluzas orientales se registró entre los jornaleros y los asalariados agrícolas que no regentaban ningún tipo de explotación rural. De acuerdo con esto último, la consecuencia más directa de esta acusadísima pérdida de población asalariada agrícola padecida por las provincias de Granada y Jaén, desde mediados de los años cincuenta hasta bien entrada la década de los setenta, fue la sustancial alteración experimentada por los valores porcentuales alcanzados por los asalariados y los no asalariados en el seno sus respectivas estructuras sociales rurales. Hacia el año 1975 , los no asalariados representaban el 66,9 por ciento de la población activa agraria de la provincia granadina, mientras los asalariados alcanzaban el 33,1 por ciento

69 Cf. AHPJ, Ministerio de Industria y Comercio, Comisaría General de Abastecimientos y Transportes: Mapa Nacional de Abastecimientos. Mapa Provincial de Abastecimientos de la provincia de Jaén, 1945; INE: Reseña Estadística de la provincia de Jaén, Madrid, Instituto Nacional de Estadística, 1956; InSTITUTO De ESTADÍsTICA DE ANDAlucía: «Evolución de la población de Andalucía» e INSTITUTO DE ESTUdIOS GIENNENSES: Anuario Estadístico de la provincia de Jaén, 1992, Tomo II: Información Municipal, Diputación Provincial, Jaén, 1993.

70 Cf. BANCO DE BILBAO: Renta Nacional de España y su distribución provincial. Serie bomogénea 1955-1975, Bilbao, 1978. 
restante $^{71}$. Por lo que respecta a la provincia de Jaén, y aunque allí tan sólo poseemos datos parciales referidos al conjunto de activos ocupados en la agricultura de forma fija y a jornada completa, hacia el año 1972 los no asalariados significaban el 83,5 por ciento de todos ellos, mientras los asalariados apenas alcanzaban el 16,5 por ciento de la población rural descrita. Si tenemos en cuenta que en la década de los 30 , justo antes de iniciarse la guerra civil, los jornaleros agrícolas de esta última provincia representaban el 39,46 por ciento de su población activa agraria, la intensidad alcanzada por la disminución de la población jornalera se nos muestra en su verdadera magnitud ${ }^{72}$. Este fenómeno de constante disminución de los efectivos jornaleros dentro de la población activa agraria, corrió paralelo a aquel otro caracterizado por el insuficiente crecimiento de una nueva clase obrera industrial, resultante del raquitismo imperante en el sector secundario y el minifundismo empresarial predominante, a lo largo de todo el régimen franquista, en el entramado económico periférico y dependiente que en todo momento prevaleció en las provincias de Granada y Jaén. Aún cuando la demostración de esto último nos apartaría tanto del cometido fundamental del presente estudio que nos vemos obligados, pues, a poner punto final al mismo.

71 Cf. Martínez Sierra, F.: Cambios estructurales en el sector agrario..., op. cit., p. 41.

72 Cf. MARTín MESA, A.: Los cambios estructurales del sector..., op. cit., p. 101. Véase asimismo BN-M: Boletín del Instituto de Reforma Agraria, (1934-1936), Censo de Campesinos de la Provincia de Jaén.

Hispania, LXIV/3, núm. 218 (2004) 1079-1112 